\title{
Experimental and soot modeling studies of ethylene counterflow diffusion flames: Non- monotonic influence of the oxidizer composition on soot formation
}

\author{
Lei Xu ${ }^{\mathrm{a}, \mathrm{b}}$, Fuwu Yan ${ }^{\mathrm{a}, \mathrm{b}}$, Mengxiang Zhou ${ }^{\mathrm{a}, \mathrm{b}}$, Yu Wang ${ }^{\mathrm{a}, \mathrm{b},{ }^{*}}$ and Suk Ho Chung ${ }^{\mathrm{c}}$
}
a. Hubei Key Laboratory of Advanced Technology for Automotive Components, School of Automotive Engineering, Wuhan University of Technology, Wuhan 430070, P.R. China
b. Hubei Collaborative Innovation Center for Automotive Components Technology, Wuhan 430070, P.R. China
c. King Abdullah University of Science and Technology (KAUST), Clean Combustion Research Center, Thuwal, Saudi Arabia

*Corresponding author:

Yu Wang

School of Automotive Engineering

Wuhan University of Technology

Wuhan, 430070, P.R. China

Email: yu.wang@,whut.edu.cn

Full-length article

Prepared for submission to Combustion and Flame 


\title{
Experimental and soot modeling studies of ethylene counterflow diffusion flames: Non- monotonic influence of the oxidizer composition on soot formation
}

\author{
Lei Xu ${ }^{\mathrm{a}, \mathrm{b}}$, Fuwu Yan ${ }^{\mathrm{a}, \mathrm{b}}$, Mengxiang Zhou ${ }^{\mathrm{a}, \mathrm{b}}$, Yu Wang ${ }^{\mathrm{a}, \mathrm{b},{ }^{*}}$ and Suk Ho Chung ${ }^{\mathrm{c}}$
}

\author{
a. Hubei Key Laboratory of Advanced Technology for Automotive Components, School of Automotive Engineering, Wuhan \\ University of Technology, Wuhan 430070, P.R. China \\ b. Hubei Collaborative Innovation Center for Automotive Components Technology, Wuhan 430070, P.R. China \\ c. King Abdullah University of Science and Technology (KAUST), Clean Combustion Research Center, Thuwal, Saudi Arabia
}

\begin{abstract}
Previous soot studies in counterflow diffusion flames revealed that the sooting limit curve in regions with large oxygen mole fractions $\left(X_{\mathrm{O}}\right)$ exhibited marked bending behaviors that indicated a non-monotonic variation of sooting tendency with oxygen concentration. The underlying mechanisms of this bending behavior remained unclear. In this regard, the present study systematically investigated the effect of oxygen mole fraction in the oxidizer stream on the sooting characteristics of ethylene counterflow diffusion flames. We used the near-infrared light extinction technique to measure the soot volume fractions of two types of flames that significantly differed in sooting structures: soot formation oxidation (SFO) flames with a fixed fuel mole fraction $\left(X_{\mathrm{F}}\right)$ of 0.28 and varying $X_{\mathrm{O}}$ between 0.5 and 1.0 and soot formation (SF) flames with pure ethylene $\left(X_{\mathrm{F}}=1.0\right)$ in the fuel stream and varied $X_{\mathrm{O}}$ from $0.25-0.3$. We also conducted detailed soot modeling studies by combining the gas-phase chemistry with a sectional soot model that accounted for soot inception, soot mass growth, particle coagulation as well as soot oxidation. Our experimental and modeling results demonstrated the non-monotonic relationship between the soot volume fractions with $X_{\mathrm{O}}$ in SFO flames. A detailed analysis of the evolutionary process of soot formation revealed that the suppression of soot inception and the enhancement of the soot oxidation process with increasing $X_{\mathrm{O}}$ led to a reduction of soot volume fraction. On the contrary, the surface growth rates increased with $X_{\mathrm{O}}$, resulting in an increase in soot mass concentration. These competing effects led to the nonmonotonic variation of soot volume fractions with $X_{\mathrm{O}}$ for SFO flames. On the other hand, in SF flames the inception and surface growth of soot both increased as $X_{\mathrm{O}}$ increased, resulting in the observed monotonic relationship between soot volume fraction and $X_{\mathrm{O}}$. We also analyzed the soot zone structures and made comparisons between SFO and SF flames.
\end{abstract}

Keywords: Sooting structures; Counterflow diffusion flame; Oxygen concentration; Sectional method 


\section{Introduction}

Combustion-generated soot emissions are known to be harmful to the environment and human health. Long-term exposure to fine soot particles can lead to a higher risk of heart and lung diseases [1]. Soot particles are also suggested to contribute significantly to regional and global climate change [2-4] by altering surface albedo and the radiative properties of the atmosphere. These adverse effects lead to increasingly stringent regulations limiting soot emissions, particularly in the transportation sector. For example, the upper limit of particulate matter (PM) emissions from heavyduty engines in the European Stationary Cycle was decreased by a factor of 10 from $0.1 \mathrm{~g} / \mathrm{kWh}$ in 2000 to $0.01 \mathrm{~g} / \mathrm{kWh}$ in 2013 [5]. To meet such stringent emission regulations, innovative technologies that inhibit soot formation in practical combustion devices are needed. Such methods require fundamental understanding of the physicochemical pathways leading from fuel molecules to condensed-phase soot particles.

In sooting flames, fuel molecules undergo various reactions to form molecular soot precursors, such as polycyclic aromatic hydrocarbons (PAHs), which nucleates out of the gas phase to produce nascent soot particles. Surfaces growth and particle-particle interactions such as coagulation then controls the particle size growth along with particle fragmentation and destructive oxidation. The whole process occurs in a rather short time scale of milliseconds and can be further complicated by complex convective/diffusive transport and turbulence in practical systems [6]. As a result, although significant efforts have been devoted as reviewed in [6-12], many fundamental aspects of soot formation process remain to be explored. Such limited knowledge motivated combustion researchers to conduct detailed studies on the sooting characteristics of laboratory-scale laminar flames in which the relatively simpler flow configuration (as compared with conditions in practical turbulent flames) makes the investigation of soot chemistry more tractable. Among these laboratory setups, a counterflow diffusion flame (CDF) has a canonical quasi-one-dimensional configuration, thus an ideal non-premixed system for experimental investigations and detailed soot model validation $[13-36]$.

A CDF can be manipulated to be sooting or non-sooting by varying the amount of $\mathrm{N}_{2}$ dilution in the fuel or oxidizer stream. For example, it was shown [37] that in an ethylene counterflow flame with no fuel side dilution (i.e., fuel mole 
fraction $X_{\mathrm{F}}=1.0$ ), soot formation could be observed only if the oxygen mole fraction in the oxidizer stream was higher than 0.18 (i.e., $X_{\mathrm{O}}>0.18$ ). As such, $X_{\mathrm{F}}=1.0$ and $X_{\mathrm{O}}=0.18$ can be regarded as a critical condition for soot formation, or as the sooting limit for ethylene counterflow flames. In a similar way, for a specified $X_{\mathrm{F}}$, a corresponding critical $X_{\mathrm{O}}$ always exists. In this regard, a sooting limit curve can be drawn in the $X_{\mathrm{F}}-X_{\mathrm{O}}$ plane that separates the sooting and nonsooting regions. To make this point clearer, a typical sooting limit curve for an ethylene counterflow diffusion flame with a nozzle exit velocity $\left(V_{0}\right)$ of $40 \mathrm{~cm} / \mathrm{s}$ is shown in Fig. 1, where the data is taken from [37]. The critical sooting conditions (open black squares) in terms of the mole fractions of fuel and oxygen were determined from scattering signals where soot signals are just about to appear, as described previously $[12,17]$. The solid line connecting these points forms the sooting limit curve, which separates the yellow-shaded sooting region from the rest of non-sooting region. The blue dashed curves, determined from equilibrium calculations, indicate constant adiabatic flame temperatures. The green dash-dot line indicates the theoretical prediction of the condition when the flame sheet is located at the stagnation plane [38]. RHS of the line corresponds to a soot formation (SF) flame where the flame sheet is located on the oxidizer side of the stagnation plane and LHS to a soot formation oxidation (SFO) flame where the flame sheet is located on the fuel side of the stagnation plane [39].

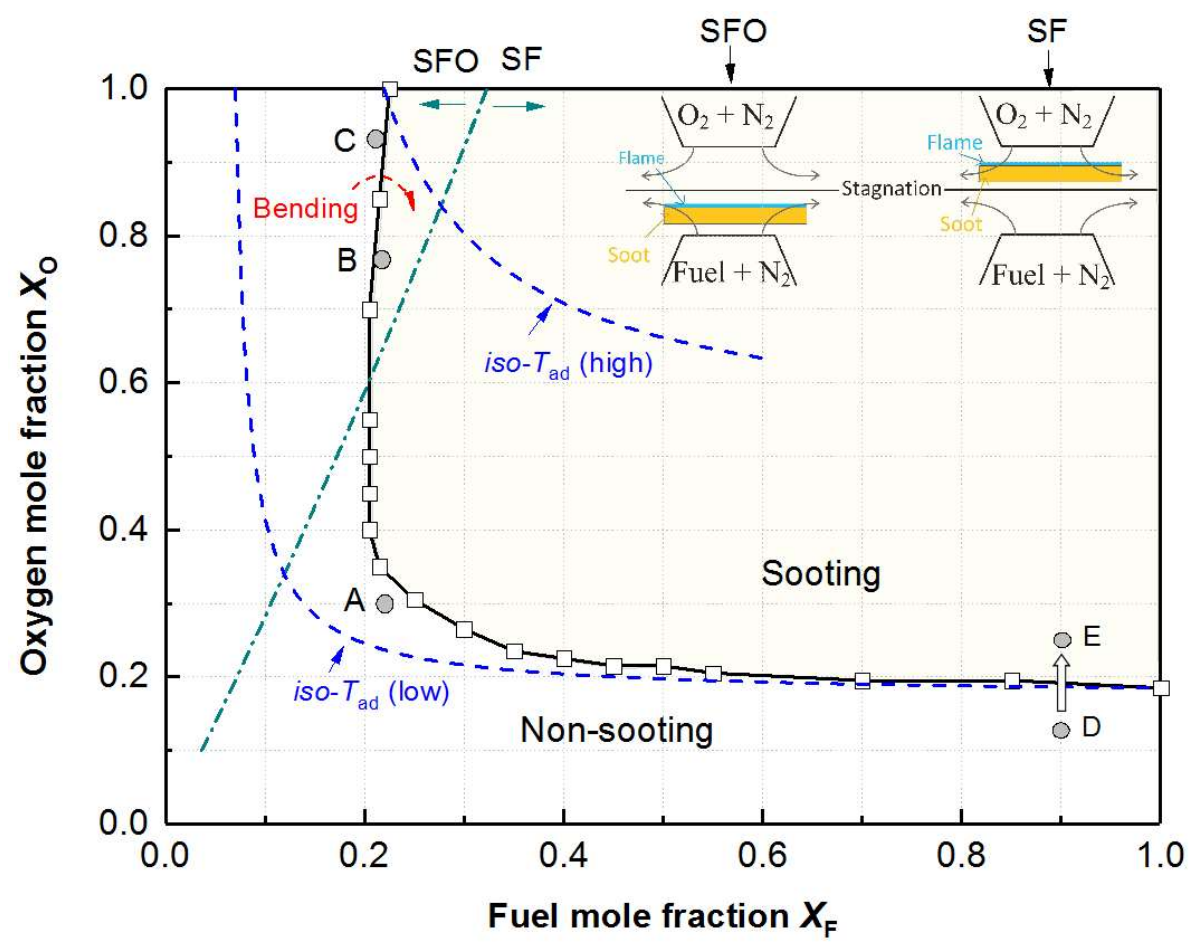

Fig. 1. Typical sooting limit map of ethylene counterflow diffusion flame in $X_{\mathrm{F}}-X_{\mathrm{O}}$ plane (data from [37]). 
The information included in this figure is rather rich and, as will be detailed later, provides much of the motivation of the present work, it is therefore worthwhile to give an elaborated explanation. Firstly, the sooting limit curve shows that starting from a pure fuel condition $\left(X_{\mathrm{F}}=1.0\right)$, the critical oxygen mole fraction $\left(X_{\mathrm{O}}\right)$ for the onset of soot formation increases slowly as $X_{\mathrm{F}}$ decreases down to a value of about 0.4 . As $X_{\mathrm{F}}$ further decreases, the critical $X_{\mathrm{O}}$ increases sharply, exhibiting a near vertical boundary. Such distinct variations indicate that there are different sooting behaviors in the large and small $X_{\mathrm{F}}$ regions caused by the transitions of flame/sooting structures. The schematics of sooting structures are illustrated qualitatively as the inset in Fig. 1. When the flame is located on the fuel side of the stagnation plane, the soot particles initially formed on the fuel side of the flame are convected toward the flame zone where the oxidizing species such as $\mathrm{OH}$ and $\mathrm{O}_{2}$ along with high temperatures lead to soot oxidation, resulting in an SFO flame. On the other hand, when the flame is located on the oxidizer side of the stagnation plane, the soot particles are convected away from the flame. This process is dominated by continuous soot growth while soot oxidation is much limited, and therefore termed as SF flame.

The second notable feature in Fig. 1 is that in SF flames with large fuel mole fraction, the sooting limits closely follow the iso-temperature curve, suggesting that soot formation is primarily controlled by temperature. This is expected as in a SF flame, soot oxidation is not present, and thus the soot loading of the flame is mainly controlled by inception and growth process, both of which are sensitive to temperature [40]. On the contrary, in SFO flames with diluted fuel streams and large $X_{\mathrm{O}}$, the sooting limits span an appreciable range of $i s o$-temperature curves, implying that temperature is not the only factor controlling soot formation in SFO flames.

The most interesting observation from Fig. 1 is that the sooting limit curve tends to bend towards the larger fuel mole fraction in the large $X_{\mathrm{O}}$ region (see the red arrow), which results in the sooting limit curve being crossed twice by a vertical line of constant $X_{\mathrm{F}}$ (e.g., the line of $X_{\mathrm{F}}=0.22$, not drawn). That is, for a fixed $X_{\mathrm{F}}$ of 0.22 as $X_{\mathrm{O}}$ increases, the initial non-sooting flame has a transition to the sooting regime (e.g., from point A to B) and then it becomes non-sooting again as $X_{\mathrm{O}}$ approaches unity (e.g., from point $\mathrm{B}$ to C), exhibiting a non-monotonic behavior with $X_{\mathrm{O}}$ for a fixed $X_{\mathrm{F}}$. In contrast, in the SF flame regime with a large fuel mole fraction (e.g., $X_{\mathrm{F}}=0.9$ ), the transition from the non-sooting to 
sooting region (from $\mathrm{D}$ to $\mathrm{E}$ ) shows a monotonic behavior with $X_{\mathrm{O}}$. Several previous studies demonstrated that the increase in oxygen concentration monotonically increased soot formation in SF flames [41-44], which can be generally attributed to thermal effects: a higher oxygen concentration led to increased flame temperature, which increased the rates of fuel pyrolysis and soot formation.

Although the bending behavior of the sooting limit curve was observed previously [37, 39, 40, 45], no detailed explanation for this behavior was provided, thus the fundamental reason is not yet clear. In addition, although the distinction in sooting structures between SF and SFO flames has been observed and discussed previously [20, 39-41], a systematic comparison of the soot evolution processes (including precursor formation, inception, surface growth, and oxidation) by adopting detailed PAH-based soot modeling, is yet to be explored. In this regard, through a combined experimental and kinetic modelling approaches, we seek to systematically investigate the effects of oxygen concentration on the sooting characteristics of both SFO and SF flames.

The fact that oxygen-enriched combustion can be potentially used to reduce soot emission also motivates this study. Previous numerical studies on counterflow diffusion flames [46-49] showed that the soot formation could be mitigated by simultaneously diluting the fuel stream and enriching the oxidizer stream. Skeen et al. [46] showed that soot formation was inhibited due to reduced concentration of soot precursor species such as benzene and phenyl, as the stoichiometric mixture fraction, $Z_{\text {stoi }}[46]$, was increased. To maintain flame temperature, the increase in $Z_{\text {stoi }}$ was achieved through simultaneously decreasing $X_{\mathrm{F}}$ and increasing $X_{\mathrm{O}}$. Du et al. [47] reported that the change in flame structure associated with an increase in $Z_{\text {stoi }}$ resulted in a shift of the $\mathrm{OH}$ concentration towards the high-temperature region, leading to a narrower soot-inception region. In a recent study, Kalvakala et al. [50] showed that reduction of soot at larger $Z_{\text {stoi }}$ was achieved through both flame structure and hydrodynamic effects. As $Z_{\text {stoi }}$ increased, the concentrations of soot precursor species, i.e., acetylene, benzene and pyrene, became decreased, which inhibited soot formation. The hydrodynamic effect resulted from a shift in the flame's location, leading to the oxidation of PAHs and soot in the oxygen-rich region. These previous studies provided deep insights into the effects of $Z_{\text {stoi }}$ on the characteristics of soot formation. However, the non-monotonic relationship between the tendency to form soot and the oxygen concentration 
with a fixed fuel stream was not observed. Naik et al. [51] conducted a sooting limit study experimentally in methaneoxygen-nitrogen counterflow diffusion flames. Their results showed that as the concentration of methane in the fuel stream increased, the concentration of oxygen in the oxidizer stream required for the inception of soot formation decreased monotonically. Consequently, the bending feature of soot limit curve was absent, leaving the non-monotonic variation of sooting tendency remain confusing. To answer this question, it is necessary to systematically investigate the effects of oxygen concentration on the sooting characteristics of both SFO and SF flames at specified fuel stream conditions. Note that the effect of oxygen concentration on soot formation characteristics have also been widely investigated in coflow diffusion flames [52-56], indicating the importance of this topic. In particular, several investigations [57-59] have demonstrated the non-monotonic variation of soot production as increasing level of fuel stream partial premixing was applied.

Specifically, we investigated the detailed sooting structures of two series of ethylene counterflow diffusion flames in this study. The first flame series featured a constant $X_{\mathrm{F}}$ of 0.28 with $X_{\mathrm{O}}$ varied from 0.5 to 1.0 , designed to reproduce the non-monotonic relationship between soot concentrations and $X_{\mathrm{O}}$ in the SFO regime and thus to elucidate the bending behavior in the sooting limit curve shown in Fig. 1. The second series were SF flames with pure ethylene $\left(X_{\mathrm{F}}=1.0\right)$ while $X_{\mathrm{O}}$ was varied from 0.25 to 0.3 . The choice of $X_{\mathrm{F}}=0.28$ in the SFO flame series was to produce flames that were moderately sooting for reliable measurements. If instead we used a value close to $X_{\mathrm{F}}=0.22$, then the soot volume fraction would be too low to be accurately measured. In the SF flame series, we did not extend $X_{\mathrm{O}}$ to unity because previous experiments showed that the variation would be monotonic $[60,61]$. The primary purpose of including the SF flames in our study was to provide a target for comparisons with the SFO flames.

As we explain in subsequent sections, the experimental and computed results consistently showed that the peak soot volume fractions first increased and then decreased as $X_{\mathrm{O}}$ increased in SFO flames, confirming the bending behavior in the sooting limit curve shown in Fig. 1. For a deeper understanding of this phenomenon, we performed a comprehensive sooting structure analysis based on the numerical results to identify the effect of the oxygen concentration on various individual processes of soot evolution. Unlike in a previous work [62] on soot modeling of SF flames using the method 
of moments, we utilized here a sectional method, which allowed us to extract detailed soot particle size distributions.

By comparing the flame structures, we show how the axial profiles of PAH concentrations, soot volume fractions, soot number density and size distribution functions differ to affect the differences in the evolution of soot formation between SFO and SF flames. Finally, we provide a fundamental explanation for the non-monotonic (monotonic) behavior with oxygen mole fraction in SFO (SF) flames.

\section{Experiment}

The axial profiles of soot volume fractions in various laminar ethylene counterflow diffusion flames were measured using the light extinction (LE) technique. The apparatus consisted of a counterflow burner, a gaseous fuel/oxidizer flowcontrol system, and a laser light extinction setup. The burner had two opposing nozzles with the fuel and oxidizer streams introduced from the lower and upper nozzles, respectively. Both nozzles had the inner diameter of $10 \mathrm{~mm}$ and the separation distance $L$ was $8 \mathrm{~mm}$. Annular slots surrounding both nozzles provided nitrogen shields to avoid disturbances from ambient air. The ethylene, oxygen and nitrogen gases were commercially pure grade with purity of $99.99 \%$. The whole burner assembly was placed on a two-dimensional translation stage with a minimum step size of $100 \mu \mathrm{m}$.

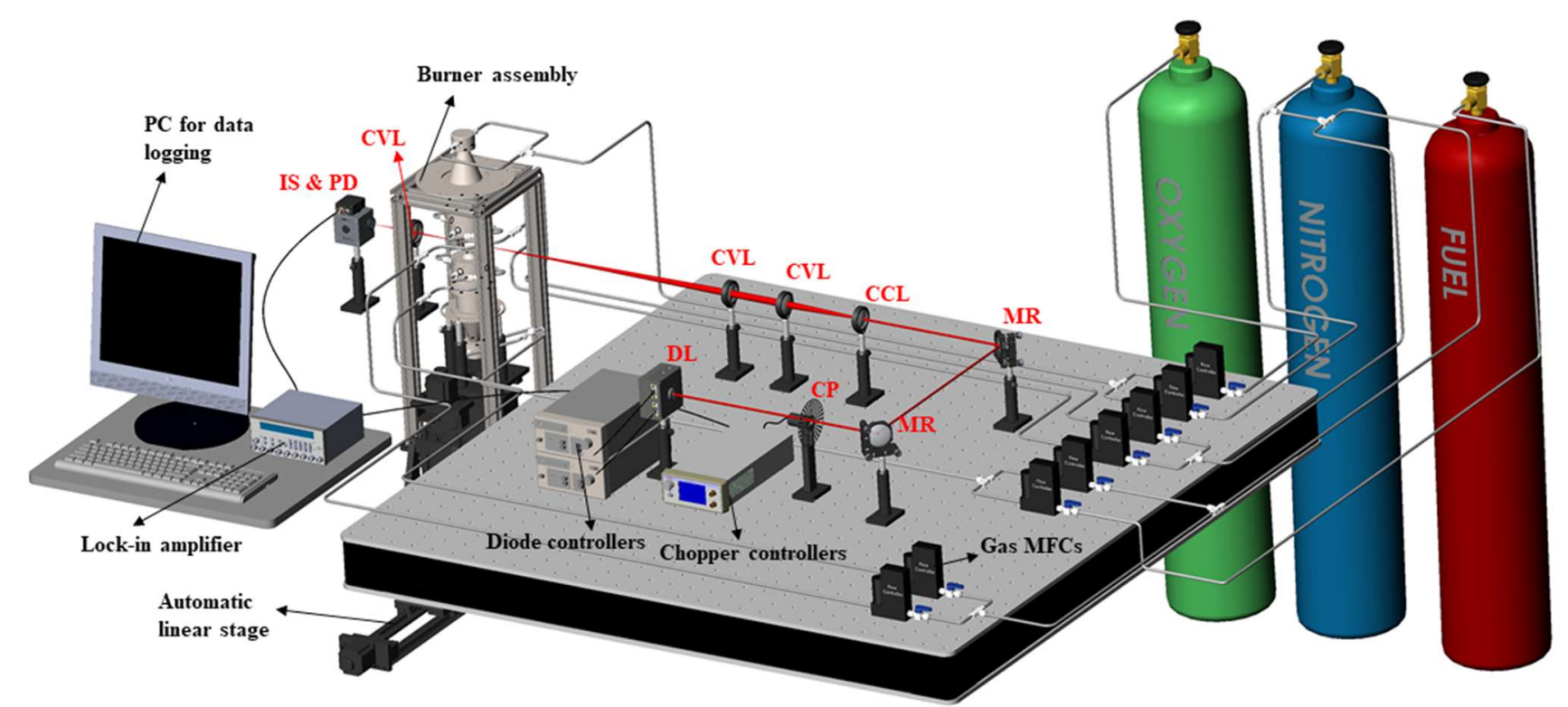

Fig. 2. Schematic of experimental apparatus showing burner assembly, gas/fuel supply system and optical/electronic components for light extinction (DL: diode laser; CP: mechanical chopper; MR: silver mirror; CCL: concave lens; CVL: 
convex lens; IS: integrating sphere; PD: photodiode).

A schematic of the light extinction setup is presented in Fig. 2. A diode laser with its center wavelength at $980 \mathrm{~nm}$ (Thorlabs; L980P010) was the light source. After passing a mechanical chopper (SRS; SR540) and re-routed by two silver mirrors, the incident beam was enlarged by a Galilean beam expander before being focused at the center axis of the burner via a convex lens $(f=1000 \mathrm{~mm})$. The focal diameter of laser beam was around $170 \mu \mathrm{m}$, as measured with knife-edge method [63]. A photodiode detector (Thorlabs; DET100A) attached to the exit port of an integrating sphere (Thorlabs; IS200-4) measured the light intensities. The optical arrangement was established through trial and error and each component was shown to be essential for reliable measurements. A quasi-one-dimensional counterflow diffusion flame features steep temperature/density gradients that may lead to appreciable beam steering [64]. The combined refocusing convex lens and integrating sphere were found to be effective in minimizing beam steering. In addition, the mechanical chopper and the digital lock-in amplifier (SRS; SR830) provided an enhanced signal-to-noise ratio, especially important under low soot conditions.

By assuming that the soot particles are within the Rayleigh scattering regime and using the data reduction procedure of Santoro et al. [65], the soot volume fraction $\left(f_{\mathrm{v}}\right)$ can be written as:

$$
f_{v}=-\frac{\lambda K_{e x t}}{6 \pi E(\widetilde{m})}
$$

where $\lambda$ is the light wavelength and $K_{\text {ext }}$ is the light extinction coefficient, which can be obtained from the measured transmittance via the Beer-Lambert law. Note that the local $K_{\text {ext }}$ for all flames were determined from the three-point Abel inversion directly [66], such that the determination of path length of light absorption was not needed. $E(\widetilde{m})$ denotes the absorption function and is dependent on the complex refractive index of soot, $\widetilde{m}$, for which a constant value of $1.57-0.56 i$ was adopted [65]. As PAH molecules are known to absorb light in the UV-Vis spectral range, they may also contribute to the extinction of the light either in the gas phase or when condensed on the surface of the soot particles. To avoid such interferences, a near-infrared diode laser at $980 \mathrm{~nm}$ was used as the light source. This choice was based on a parallel study in which the spectral dependence (from 405 to $1064 \mathrm{~nm}$ ) of soot extinction in counterflow diffusion flames was systematically investigated. We observed that the measured soot volume fraction became nearly independent 
of $\lambda$ when $\lambda>780 \mathrm{~nm}$. We note that previous studies based on premixed or coflow diffusion flames also recommended wavelength larger than $800 \mathrm{~nm}$ for light extinction measurements [67-71].

As mentioned before, we measured soot characteristics in two series of ethylene counterflow diffusion flames that differed in the fuel/oxidizer compositions. The detailed flow rate conditions are summarized in Table S1 of the supplementary material (SM). The nozzle exit velocities for both the fuel and oxidizer streams were maintained at $U_{0}=$ $20 \mathrm{~cm} / \mathrm{s}$. Thus, the global strain rate $\alpha_{\mathrm{g}}$ was maintained at $a_{\mathrm{g}}=100 \mathrm{~s}^{-1}$ based on $4 U_{0} / L$ [14]. The nozzle outlet temperature and pressure were maintained at ambient conditions.

\section{Numerical simulation}

To provide insights beyond the experimental observations, we conducted numerical simulations of soot formation by coupling a detailed gas-phase kinetic mechanism of KAUST PAH Mech 2 (KM2) [72] with a recently proposed PAHbased soot model [62]. KM2 was developed by extending the USC II mechanism [73] for $\mathrm{H}_{2} / \mathrm{CO} / \mathrm{C}_{1}-\mathrm{C}_{4}$ fuels to account for PAH growth up to coronene; it consists of 202 species and 1351 reactions. The soot model [62] accounts for soot inception from large PAH molecules, surface growth, PAH condensation, particle-particle coagulation as well as soot oxidation by $\mathrm{OH}$ and $\mathrm{O}_{2}$. Model validation against experimental data including the gas-phase soot precursors measured by Senkan and coworkers [34, 35], soot volume fraction, and average diameters, have been performed in a previous work [62]. More details of the soot model can be found in [62] and only a brief summary is provided here.

Soot inception was modeled by the formation of PAH dimers. Eight PAH species with sizes larger than pyrene were allowed to form dimers via a total of $36\left(\mathrm{C}_{8}^{2}=28\right.$ heterogeneous +8 homogeneous dimerization $)$ nucleation reactions, which were assumed to be irreversible with zero activation energy. Considering the steric effect and the fact that excess collision energy may result in the rebound of colliding molecules, not every collision between two PAH molecules will lead to successful dimer formation. This is captured in the model by collision efficiencies, which depend on the size of the nucleating PAHs [74]. Once particles are incepted, they grow in size via both surface reactions and particle-particle coagulation. The chemical surface growth is described by the hydrogen-abstraction- $\mathrm{C}_{2} \mathrm{H}_{2}$-addition (surface-HACA) 
scheme proposed by Frenklach and co-workers $[75,76]$. Here, we also included $\mathrm{H}$ abstraction reactions by $\mathrm{CH}_{3}, \mathrm{C}_{3} \mathrm{H}_{3}$ and $\mathrm{C}_{2} \mathrm{H}$ radicals (modified surface $\mathrm{HACA}$ ) as inspired by the results of a previous study [40]. Along with such surface chemical reactions, the physical soot mass addition process from PAH condensation was also considered. In the PAH condensation model, a PAH-soot collision efficiency was introduced to accommodate only a certain percentage of PAH collisions can lead to successful PAH addition onto soot surface. The details of the soot inception reactions, HACA reaction sequence and PAH condensation reactions can be obtained from the supplementary file in the previous work [62]. In this work, all the model parameters have been used consistently with ref. [62], except for the HACA acetylene addition reaction of $\mathrm{C}_{\text {soot }}+\mathrm{C}_{2} \mathrm{H}_{2} \Rightarrow \mathrm{C}_{\text {soot }}-\mathrm{H}+\mathrm{H}$, which will be discussed later.

Particle coagulation, the merging of two small particles into a bigger one, alters particle size distribution while preserving the total soot mass. In the present simulation, coagulation was assumed to be in the free-molecular regime, with a collision efficiency of 2.2 considering the van der Waals enhancement [77]. The soot oxidation by $\mathrm{OH}$ and $\mathrm{O}_{2}$ was also included. A constant collision efficiency $\gamma_{\mathrm{OH}}$ of 0.13 is assumed by $\mathrm{OH}$ radicals [78] while soot oxidation rates with $\mathrm{O}_{2}$ were taken from Celnik et al. [79], although several recent studies suggested that the oxidation rates of soot depend on its chemical composition and internal structures [80-83]. Particle aggregation and fragmentation was not considered in this work.

We used a sectional method [84-86] to model the particle dynamics. The sectional method has an advantage of being able to resolve the particle size distribution function while the method of moments [87], which we used in our previous studies [62, 88], gives only statistical information (moments) about the size distribution. The range of soot mass /volume is divided into 25 sections with a spacing factor of 2 (i.e., the mass/volume ratio of two consecutive sections is 2), with the first section contains a dimer from pyrene dimerization, i.e., 32 carbon atoms. In each section, all the soot particles are assumed to be spherical with a density of $1.8 \mathrm{~g} / \mathrm{cm}^{3}$ [89]. In such context, the present simulations covered sectional representative sizes with a range of $0.878-224.8 \mathrm{~nm}$. The lower limit is consistent with a previous experimental finding that the smallest particle diameter found was around $1 \mathrm{~nm}$ [90]. The choice of the upper limit of the section number should cover the maximum soot diameter that may appear and is thus dependent on actual sooting system investigated. 
Note that we have confirmed extending the section number range have no effects on the simulations.

Thermophoresis, which plays an important role in the transport of soot particles [91], was also considered in the present simulations. The position of the particle stagnation plane was experimentally observed to shift noticeably toward the fuel side by the thermophoretic effect [39], thus the thermophoretic effect should be considered in soot simulation of in counterflow diffusion flames that have a strong axial temperature gradient. Gas-phase radiation heat transfer from species $\left(\mathrm{CH}_{4}, \mathrm{CO}, \mathrm{CO}_{2}\right.$ and $\left.\mathrm{H}_{2} \mathrm{O}\right)$ and soot particle radiation were considered in the transport equation of energy [92]. The coupled transport equations of the gas-phase species and number density were numerically solved with the opposed flow module of the Chemkin Pro package [93]. A segregated approach was utilized to speed up convergence. The gasphase equations were solved first, and the results were fed to the particle phase during which the consumption rates of the gas-phase species due to soot formation and oxidation were evaluated as sink terms and were iterated back into the gas phase. These iterative steps continued until a prescribed convergence criterion was met.

\section{Results and discussions}

\subsection{Soot volume fraction: Experimental and numerical results}

Before presenting a detailed analysis of the oxidizer composition effect, we first validate the soot model by comparing the experimental and predicted soot volume fraction profiles of both SF and SFO flames. As mentioned above, the soot surface reaction mechanism used in the present work follows a previous study [62] in which validation was done in an ethylene SF flame $\left(X_{\mathrm{F}}=1.0, X_{\mathrm{O}}=0.25\right)$ for the effects of fuel dopant $\left(\mathrm{CH}_{4}, \mathrm{C}_{2} \mathrm{H}_{6}\right.$ and $\left.\mathrm{C}_{3} \mathrm{H}_{8}\right)$. However, the performance of this mechanism in predicting the sooting structures of SFO flames as well as the effects of $X_{\mathrm{O}}$ on soot formation have not yet been explored. Furthermore, the present work utilized a sectional method for particle dynamics, which is fundamentally different from the previously used method of moments with interpolative closure. These changes in flame environments and numerical approaches required additional validations.

In this regard, we first compared the experimental and simulated soot volume fractions for typical $\mathrm{SF}\left(X_{\mathrm{F}}=1.0, X_{\mathrm{O}}=0.3\right)$ and SFO flames $\left(X_{\mathrm{F}}=0.28, X_{\mathrm{O}}=0.9\right)$. As shown in Fig. 3, the simulated axial profiles of soot volume fraction agreed 
satisfactorily well with the experimental data: the nearly symmetric soot profile of the SFO flame (a) and the highly skewed feature of the SF flame (b) were both captured. In addition, the predicted sudden drop in soot concentrations across the particle stagnation plane of the SF flame was also found in the experimental evidence. This large gradient is the reason why sufficient spatial resolution in soot measurements is essential.

This overall level of agreement between the experiments and simulations was encouraging as this agreement indicated the capability of the present soot model to resolve the sooting structures of both SF and SFO flames, the understanding of which is a prerequisite for further investigation of the drastically different behaviors present in the sooting limit curve between SF and SFO regimes. In addition to the soot profiles, the absolute values of the peak soot volume fraction were also well predicted. This, however, has to be understood with the knowledge that a parameter $\alpha$, which represents the fraction of active sites available for surface HACA growth according to Appel et al. [76], was generally tuned to match the experimental data in previous studies $[94,95]$. Such free surface sites become unreactive through soot aging. As a result, $\alpha$ is expected to be dependent on soot maturity (in turn on soot surface temperature, among other things), thus should vary depending on SF and SFO flame conditions in this work. However, since a first-principle based expression of temperature-dependent $\alpha$ is not available, we rather choose a constant value to avoid unnecessary arbitrariness. The net effect of including $\alpha$ influence in our simulations is considered by adjusting the acetylene-adding reaction rate of $\mathrm{C}_{\text {soot }}+\mathrm{C}_{2} \mathrm{H}_{2} \Rightarrow \mathrm{C}_{\text {soot }} \mathrm{H}+\mathrm{H}$ in the surface HACA mechanism, which is achieved by adjusting its pre-exponential factor $A_{\mathrm{HACA}}$ [76]. The value of $1.45 \times 10^{7}$ was determined to match the maximum soot volume fraction (SVF) of a base SFO flame $\left(X_{\mathrm{F}}=0.28, X_{\mathrm{O}}=0.9\right)$ and it was kept constant in all SFO flame simulations. For SF flames, a larger value of $A_{\mathrm{HACA}}=1.0 \times 10^{8}$ was adopted, which is reasonable considering that the surface temperature of soot in SF flames (around $1580 \mathrm{~K}$ in the center of the sooting zone) is significantly lower than in SFO flames ( $2150 \mathrm{~K})$ such that soot aging occurs to a much lesser extent in SF flames. Note that the quantitative difference (from a reference value of $8.0 \times 10^{7}$ recommended by Appel et al. [66]) can be reasonable considering that soot inception and growth models are different. 


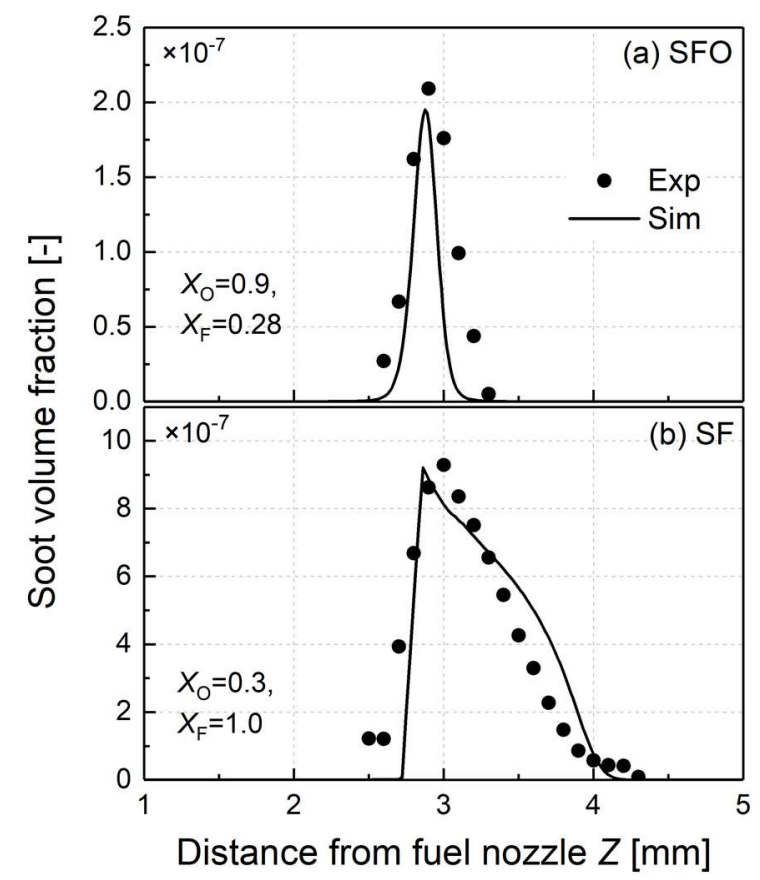

Fig. 3. Comparison between experimental and computed soot volume fraction profiles $\mathrm{C}_{2} \mathrm{H}_{4}$ counterflow diffusion flames for (a) soot formation-oxidation structure $\left(X_{\mathrm{F}}=0.28, X_{\mathrm{O}}=0.9\right)$ and (b) soot formation structure $\left(X_{\mathrm{F}}=1.0, X_{\mathrm{O}}=0.3\right)$. The experimental data for both flames was shifted towards the oxidizer side by $0.3 \mathrm{~mm}$.

We next tested the model performance in predicting the effect of oxygen mole fraction $\left(X_{\mathrm{O}}\right)$ on soot formation. Comparisons between the experimental and simulated soot volume fraction profiles with varying $X_{\mathrm{O}}$ are shown in Fig. 4 and Fig. 5 for $\mathrm{SFO}\left(X_{\mathrm{F}}=0.28, X_{\mathrm{O}}=0.5-1.0\right)$ and $\mathrm{SF}\left(X_{\mathrm{F}}=1.0, X_{\mathrm{O}}=0.25-0.3\right)$ flames, respectively. The numerical results agree well with the experiments in that all the varying trends with $X_{\mathrm{O}}$ are well captured. Specifically, for SFO flames (Fig. 4), as $X_{\mathrm{O}}$ increases from 0.5 to 1.0 , the locations of the peak soot concentrations shift progressively towards the fuel side. This can be understood by noting that enriched oxygen in the oxidizer stream has the effect of decreasing the stoichiometric mixture fraction, which in turn moves the stoichiometric plane (i.e., flame sheet) closer to the fuel stream. Since soot always starts to form on the fuel-rich side of the flame, it is reasonable to expect the sooting zone to shift along with the flame. An even more important observation regarding the effect of $X_{\mathrm{O}}$ is that the peak soot volume fraction first increases, reaching a maximum value near $X_{\mathrm{O}}=0.7$, and then decreases as $X_{\mathrm{O}}$ further increases. This interesting non-monotonic variation of soot volume fraction with $X_{\mathrm{O}}$, which was successfully predicted by the model, explains the bending behavior of the sooting limit curve in the small $X_{\mathrm{F}}$ region. It is noted in Fig. 4 that quantitatively, the computed peak soot volume fractions exhibit a stronger variation with $X_{\mathrm{O}}$ than do the experimental data. This can be partly 
attributed to the assumption of constant $\alpha$ (i.e., constant $\left.A_{\mathrm{HACA}}\right)$ which should vary with flame temperature as $X_{\mathrm{O}}$ changes.

We also note that the predicted soot zone thickness is somewhat narrower than the experimental results in SFO flames.

Such deviations can be partly attributed to the spatial resolution of the incident laser beam with the diameter around 170 $\mu \mathrm{m}$. As a result, the spatial blurring effect may cause an experimental over-estimation of the actual sooting zone thickness and thus contribute to the discrepancies. Uncertainties of soot model parameters may also lead to the discrepancies of predicted and experimental soot zone thickness. Although the present soot model could not perfectly capture all the quantitative aspects of soot formation, the non-monotonic variation of sooting tendency with $X_{\mathrm{O}}$ for SFO flames and the monotonic variation in SF flames in Fig. 5 are well captured, which is the primary research objective and thus the soot model is believed to serve the purpose.

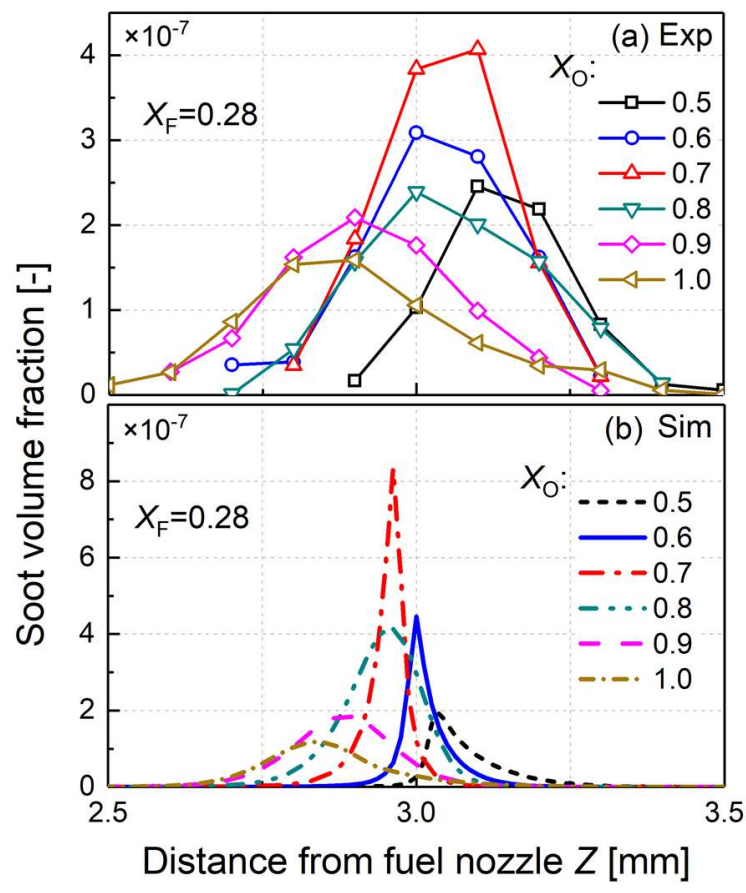

Fig. 4. Comparison between (a) experimental and (b) computed soot volume fraction profiles of $\mathrm{C}_{2} \mathrm{H}_{4}$ counterflow diffusion flames for soot formation-oxidation flames $\left(X_{\mathrm{O}}=0.5-1.0 ; X_{\mathrm{F}}=0.28\right)$.

The results for SF flames shown in Fig. 5 are consistent with previous studies $[41-43,61,96]$ in that the increase in $X_{\mathrm{O}}$ increases soot formation, as the flame temperature increases with $X_{\mathrm{O}}$. A higher flame temperature in SF flames results in increased rates of fuel pyrolysis, precursor formation, and particle surface growth, all of which contribute to the 
increased soot volume fraction. This dominance of the thermal effect in soot formation is also seen in Fig. 1, where the sooting limit curve closely follows the iso-temperature curve in the SF flame regime. However, the thermal effect itself cannot explain the non-monotonic relationship between the peak soot volume fraction with $X_{\mathrm{O}}$ in SFO flames in which the predicted maximum flame temperature reasonably increase linearly with $X_{\mathrm{O}}$ from $2560 \mathrm{~K}\left(X_{\mathrm{o}}=0.5\right)$ to $2835 \mathrm{~K}$ $\left(X_{\mathrm{O}}=1.0\right)$. This result suggest that the effect of $X_{\mathrm{O}}$ on sooting behavior is dependent on the flame's structure.

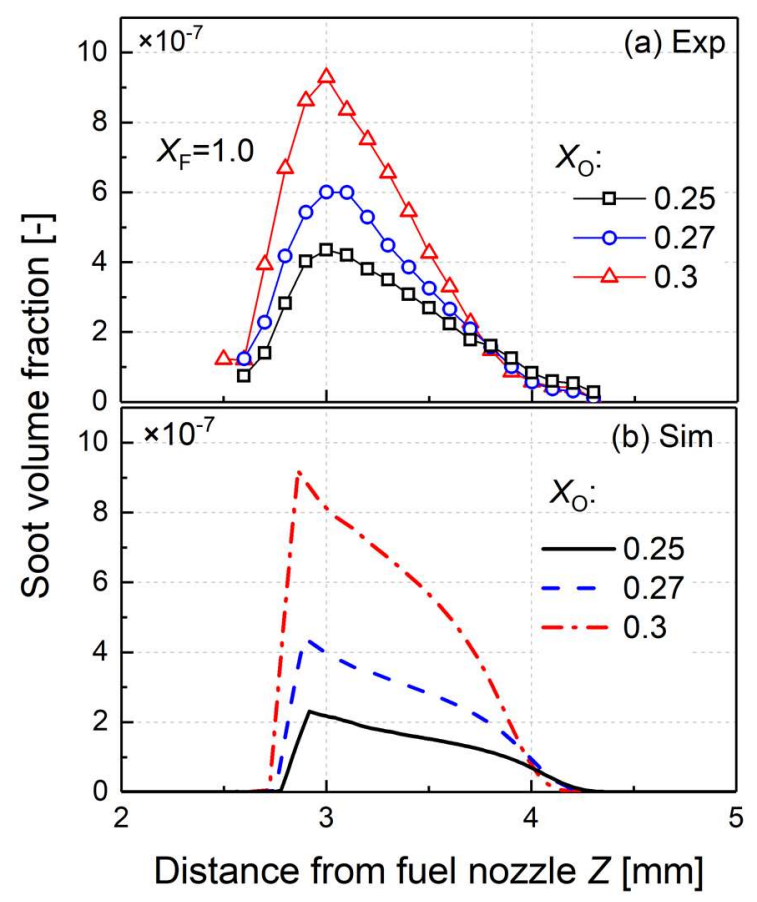

Fig. 5. Comparison between experimental and computed soot volume fraction profiles in $\mathrm{C}_{2} \mathrm{H}_{4}$ counterflow diffusion flames for soot formation flames $\left(X_{\mathrm{O}}=0.25-0.3 ; X_{\mathrm{F}}=1.0\right)$ (simulation data are averaged over $170 \mu \mathrm{m}$ considering laser beam diameter).

\subsection{Detailed analysis of sooting structures}

Comprehensive knowledge of the sooting structures of SF and SFO flames is required for the analysis of their different dependences on $X_{\mathrm{O}}$. In this section, we discuss how changes in flame structures affect the evolution of soot particles in flames. Detailed thermal and chemical structures of the soot zones in a typical SFO flame $\left(X_{\mathrm{F}}=0.28, X_{\mathrm{O}}=0.9\right)$ and SF flame $\left(X_{\mathrm{F}}=1.0, X_{\mathrm{O}}=0.3\right)$, treated here as the baseline SFO and SF flame are presented in Fig. 6 to contrast the differences between SF and SFO flames in the processes of soot inception, coagulation, surface growth, and oxidation.

The simulation results show the predicted profiles of temperature as well as the mole fractions of selected important 
species (a, e), the mole fractions of the molecular precursors of soot $(b, f)$, soot number density and average diameters (c, g) and soot volume fractions (d, h) for the SFO (left) and SF (right) flames. The positions of the flame sheet as represented by the maximum temperature location $\left(Z_{\max }\right)$ and the particle stagnation plane $\left(Z_{\mathrm{st}, \mathrm{g}}\right)$ are both marked. As an important soot growth agent through the HACA reaction scheme, acetylene $\left(\mathrm{C}_{2} \mathrm{H}_{2}\right)$ appears only on the fuel side of the flame in both flames $(\mathrm{a}, \mathrm{e})$, indicating that $\mathrm{C}_{2} \mathrm{H}_{2}$ is primarily produced from fuel pyrolysis. In Fig. $6 \mathrm{~b}$ and $\mathrm{f}$ of both flames, A1-A4 refers to aromatic species with 1-4 rings, following the same notation as in our previous study [72]. Benzene (A1) and PAHs (A2-A4) are also abundant in this fuel-rich region, consistent with the fact that $\mathrm{C}_{2} \mathrm{H}_{2}$ is an important building block for PAH growth.
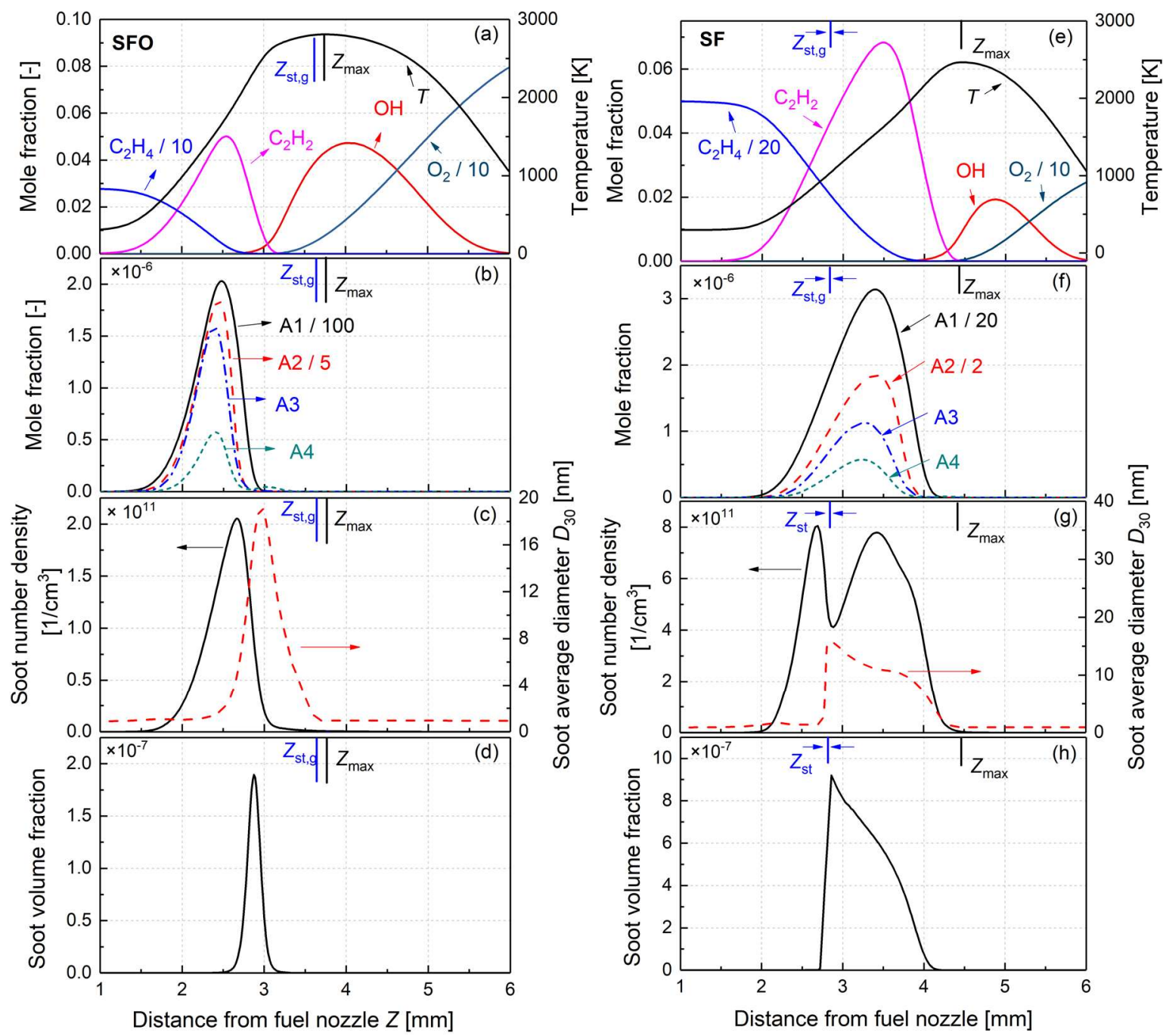

Fig. 6. Comparisons in the simulated profiles between the baseline $\mathrm{SFO}\left(X_{\mathrm{F}}=0.28, X_{\mathrm{O}}=0.9\right)$ and $\mathrm{SF}\left(X_{\mathrm{F}}=1.0, X_{\mathrm{O}}=0.3\right)$ flames; $(a, e)$ temperature and mole fractions of selected species, (b, f) molecular precursors of soot, (c, g) soot number density and diameter, and $(\mathrm{d}, \mathrm{h})$ soot volume fraction. 
However, the flame structures between SFO and SF flames differ significantly in many aspects. Firstly, in the baseline SFO flame, the flame sheet $\left(Z_{\max }\right)$ and stagnation plane $\left(Z_{\mathrm{st}, \mathrm{g}}\right)$ are very close to each other such that the oxidizing zone sits across the stagnation plane. This means that an appreciable amount of $\mathrm{OH}$ radicals exist on both the fuel and oxidizer sides of the flame sheet, which is confirmed by the $\mathrm{OH}$ axial profile (Fig. 6a). An important implication is that as the soot particles (initially formed on the fuel side of flame) are directed toward the stagnation plane, significant soot oxidation takes place as the particles approach the high-temperature $\mathrm{OH}$ oxidizing region. While in the SF flame, the separation distance between the flame sheet $\left(Z_{\max }\right)$ and the stagnation plane $\left(Z_{\mathrm{st}, \mathrm{g}}\right)$ is much larger than that of the SFO flame. As a consequence, unlike in the SFO flame, the oxidizing zone in SF flame does not cover the stagnation plane. Secondly, although for the SF flame, the fuel pyrolysis products such as $\mathrm{C}_{2} \mathrm{H}_{2}$ and PAHs remain on the fuel side of the flame, but the peaks of the $\mathrm{C}_{2} \mathrm{H}_{2}$ and PAHs profiles are located between the flame and the stagnation plane. This behavior is different from the distribution in the SFO flame, where the whole PAH region is located on the fuel side of the stagnation plane. These changes in the flame structure results in different sooting behavior as compared with the SFO flame, as can be noticed from the axial profiles of soot number density and soot volume fraction shown in Figs. $6 \mathrm{c}$ and d.

In SFO flame, the soot number density increases simultaneously with PAHs until reaching a peak near $Z=2.5 \mathrm{~mm}$. Interestingly, despite the continuous increase of soot number density in the region of $Z=1.5-2.5 \mathrm{~mm}$, the soot volume fraction profile (d) still maintains a very small level. This is because for relatively small $Z$, the flame temperature is rather low and, consequently, mass-adding reactions such as surface HACA reactions, unlikely occur. This is supported by reaction rate analysis as detailed in Fig. 7a, where the rates including the summation of 36 soot inception reactions, HACA surface growth, and soot oxidation with $\mathrm{OH}$ radical are shown. As can be seen, the surface HACA reaction hardly occurs in the region of $Z=1.5-2.5 \mathrm{~mm}$. This implies that the newly incepted particles do not easily grow in size, leading to negligible contribution to soot volume fractions. As the particles further convect from $Z=2.5 \mathrm{~mm}$ toward the particle stagnation plane $\left(Z_{\mathrm{st}, \mathrm{g}}\right)$, the HACA surface growth becomes important. Consequently, both soot volume fraction and soot average particle diameter (defined as volume-averaged diameter $D_{30}[65]$ ) increase rapidly and reach their peaks near $Z$ 
$=2.8 \mathrm{~mm}$. Note that the nearly symmetric shape of soot diameter profile in SFO flame is consistent with the previous measurement result [39]. While the particle diameter increases for $Z>2.5 \mathrm{~mm}$, the number density (Fig. 6c) shows a decreasing trend, which is likely caused by particle-particle coagulation. For $Z>2.8 \mathrm{~mm}$, the increase in $\mathrm{OH}$ radical and $\mathrm{O}_{2}$ concentrations enhance soot oxidation, resulting in a decrease in both soot volume fraction and the average particle diameter. Note the soot particles are completely oxidized (i.e., soot volume fraction becomes zero) even before reaching the stagnation plane, which is consistent with a previous experimental observation that SFO flames are smoke free (i.e., no smoke is emitted from the flame) [39]. The complete evolution of soot, from inception and surface growth to destructive oxidation, which all occur on the fuel side of the stagnation plane, result in a symmetric profile of the soot volume fraction for the SFO flames.

In contrast, the profile of soot volume fraction of SF flame (Fig. 6h) is highly skewed toward the fuel stream. As mentioned previously, soot always begins to form on the fuel-rich side of the flame. In the SF flame scenario, incipient soot particles are transported away from the oxidizing zone. Specifically, as the newly formed particles near $Z=4.2 \mathrm{~mm}$ are brought leftward by convection toward the stagnation plane, the mass-adding surface HACA reactions continue to occur but the mass-diminishing soot oxidation reactions are limited due to the almost non-existent of $\mathrm{O}_{2}$ and $\mathrm{OH}$ in this region. As confirmed in Fig. 7b, the soot oxidation rate is negligible in the near stagnation plane region of $Z=3.5-2.8$ $\mathrm{mm}$. As a result, the soot volume fraction continuously increases along the direction of convection from $Z=4.2$ to 2.8 $\mathrm{mm}$, along with the continuous increase in soot average diameter. The sudden drop of soot volume fraction across the stagnation plane is because the particles have very low diffusivity and thus cannot effectively penetrate through the plane where the axial convection velocity is 0 . What physically occurs is the radial leakage of the soot particles out of the flame. SF counterflow flames are thus known to be smoky, as was visualized in [39].

The soot number density profile of SF flames is also different from that of SFO flames. Figure $6 \mathrm{~g}$ shows that soot number density profile has double peaks with a trough located at the stagnation plane. This means that on the fuel side of the stagnation plane, soot particles are forming in the region of $Z=2.0-2.8$. This is because PAH molecules are present in this region and the physical collision between PAHs leads to the formation of soot nuclei. This result is 
consistent with the experimental observations of D'Anna et al. [27] who demonstrated that abundant small-size particles exist in the lower temperature region (pyrolytic region on the fuel side of the particle stagnation plane) in an ethylene SF flame. However, different from the high-temperature region (near $Z=4.2 \mathrm{~mm}$ ), the mass growth of soot via the HACA mechanism are inhibited on the pyrolytic region on the fuel side of the stagnation plane, primarily due to the low flame temperature $(<1000 \mathrm{~K})$. Consequently, the newly formed soot particles cannot grow as they are transported toward the

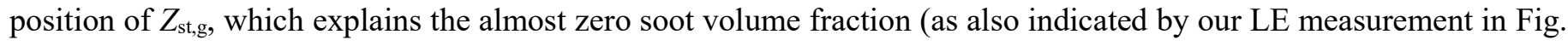
5). Note that this result may seem to be different from the works of D'Anna and coworkers $[27,28]$ in which, a shoulder of soot profile was detected in the pyrolytic region. This difference can be partially attributed to the different optical methods used for soot measurements. Note the nascent small-size particles in the pyrolytic region may have notably different optical properties as compared to mature graphitic soot: they could even be liquid-like [7,97] and transparent to visible and near infrared lights and thus cannot be detected efficiently with the present LE technique. On the other hand, these nanoparticles may well response to the laser-induced emission spectrum method used in Refs. [27, 28] in which, a UV laser was used as the probe light source. However, although the potential absence of nascent particles in the current experimental measurements, our simulations indicated that these small-size particles (e.g., $\left.D_{\mathrm{P}}<10 \mathrm{~nm}\right)$ account for negligible volume fraction and therefore have minor effects on the behavior of peak soot volume fraction.

The number of soot particles is determined by the competition between soot inception and particle-particle coagulation. The decrease in soot number density toward $Z_{\mathrm{st}, \mathrm{g}}$ from both sides is partially a result of particle coagulation. A comparison of particle size distribution (PSD) for SF and SFO flames are presented in the supplementary material with some discussions. 


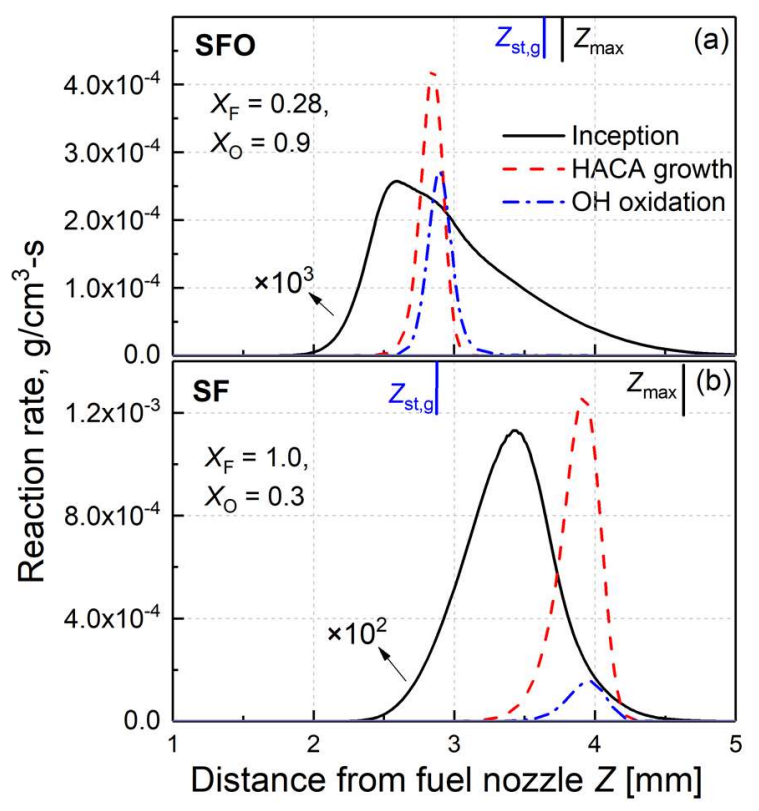

Fig. 7. Reaction rates of total soot inception, HACA surface growth and OH-induced soot oxidation in SFO (a) and SF (b) flames. Note that soot oxidation by $\mathrm{O}_{2}$ is minor compared to $\mathrm{OH}$-induced oxidation and thus not shown.

\subsection{Effect of $X_{\mathrm{O}}$ on soot formation}

The above discussion provides information on how soot particles are formed and evolved in typical SFO and SF flames. The experimental data in Figs. 4 and 5 showed that depending on the flame structure, the effect of oxidizer concentration $X_{\mathrm{O}}$ on soot formation is different in the two types of flames. In this section, we analyze the underlying mechanisms responsible for the non-monotonic relationship between the peak soot volume fraction in SFO flames and $X_{\mathrm{O}}$ from the perspective of $\mathrm{PAH}$ growth, soot inception, soot growth, and soot oxidation. Comparisons with the monotonic relationship in SF flames are also provided.

We first look at the effect of $X_{\mathrm{O}}$ in SFO flames $\left(X_{\mathrm{F}}=0.28\right)$. As was shown in Fig. 4, the maximum SVF in SFO flames $\left(X_{\mathrm{F}}=0.28\right)$ first increased and then decreased as $X_{\mathrm{O}}$ increased from 0.5 to 1.0 with its peaks near $X_{\mathrm{O}}=0.7$. To understand this phenomenon, soot modelling was performed and the numerical results were analyzed in detail for $X_{\mathrm{O}}=0.6,0.7$ and 0.9. Figure 8 shows the SVF profiles (a) and volumetric PSDs $\left(\mathrm{d} V / \mathrm{d} \log D_{\mathrm{p}}\right)$ at peak SVF location (b). Compared to the case of $X_{\mathrm{O}}=0.6$ and 0.9 , the large-size particles for $X_{\mathrm{O}}=0.7$ are more abundant which accounts for its largest soot volume fractions. 

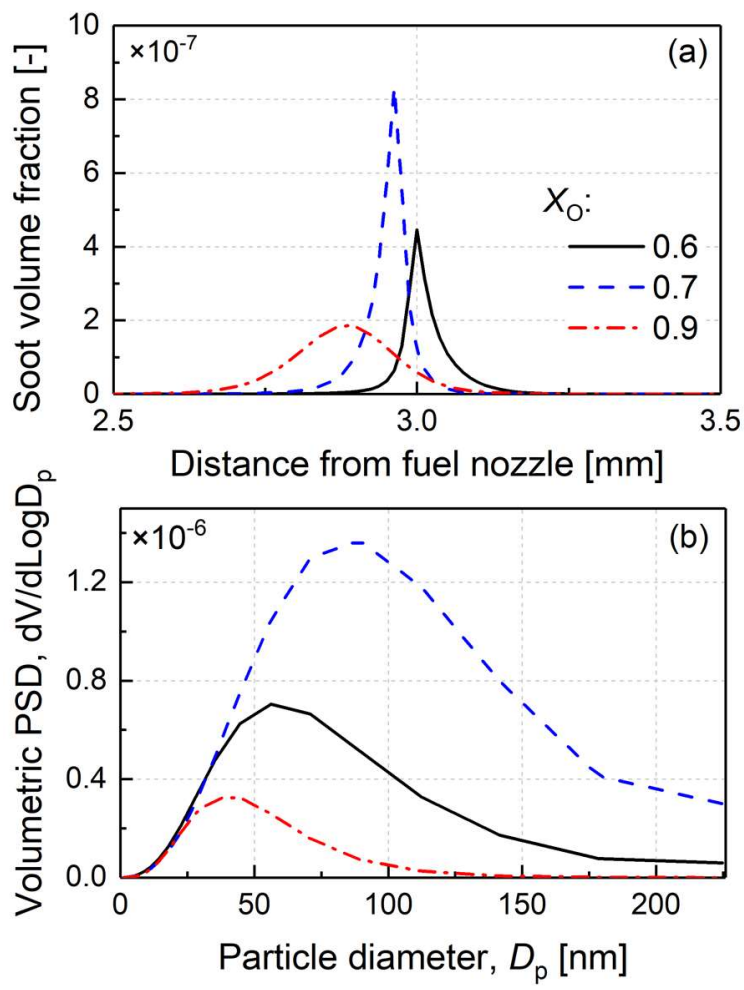

Fig. 8. Computed soot volume fraction (a) and volumetric PSD (dV/dlog $D$ p) (b) at peak SVF location for SFO flames $\left(X_{\mathrm{F}}=0.28 ; X_{\mathrm{O}}=0.6,0.7\right.$ and 0.9$)$.

To further elucidate the reasoning, the profiles of temperature and important intermediate species responsible for soot formation are shown in Fig. 9 for varying $X_{\mathrm{O}}$. The results show that, as $X_{\mathrm{O}}$ increases from 0.6 to 0.9 , the location of the maximum temperature moves slightly toward the fuel side. The change in the position of the stagnation plane is observed to be negligible (not shown, less than $0.1 \mathrm{~mm}$ ), demonstrating that the variation of $X_{\mathrm{O}}$ does not change the overall sooting structure of SFO flames (the oxidizing zone always cover the stagnation plane). The maximum flame temperature (a) increases with $X_{\mathrm{O}}$, which is due to the reduced $\mathrm{N}_{2}$ dilution in the oxidizer stream. Although peak concentrations of $\mathrm{C}_{2} \mathrm{H}_{2}$ (b) and $\mathrm{C}_{3} \mathrm{H}_{3}$ (c) increase with $X_{\mathrm{O}}$, the peak concentration of benzene (d) remains nearly unchanged, while the peak concentrations of the large aromatic species, such as pyrene (A4) and coronene (A7), show decreasing trends with $X_{\mathrm{O}}$ $(\mathrm{e}, \mathrm{f})$. 

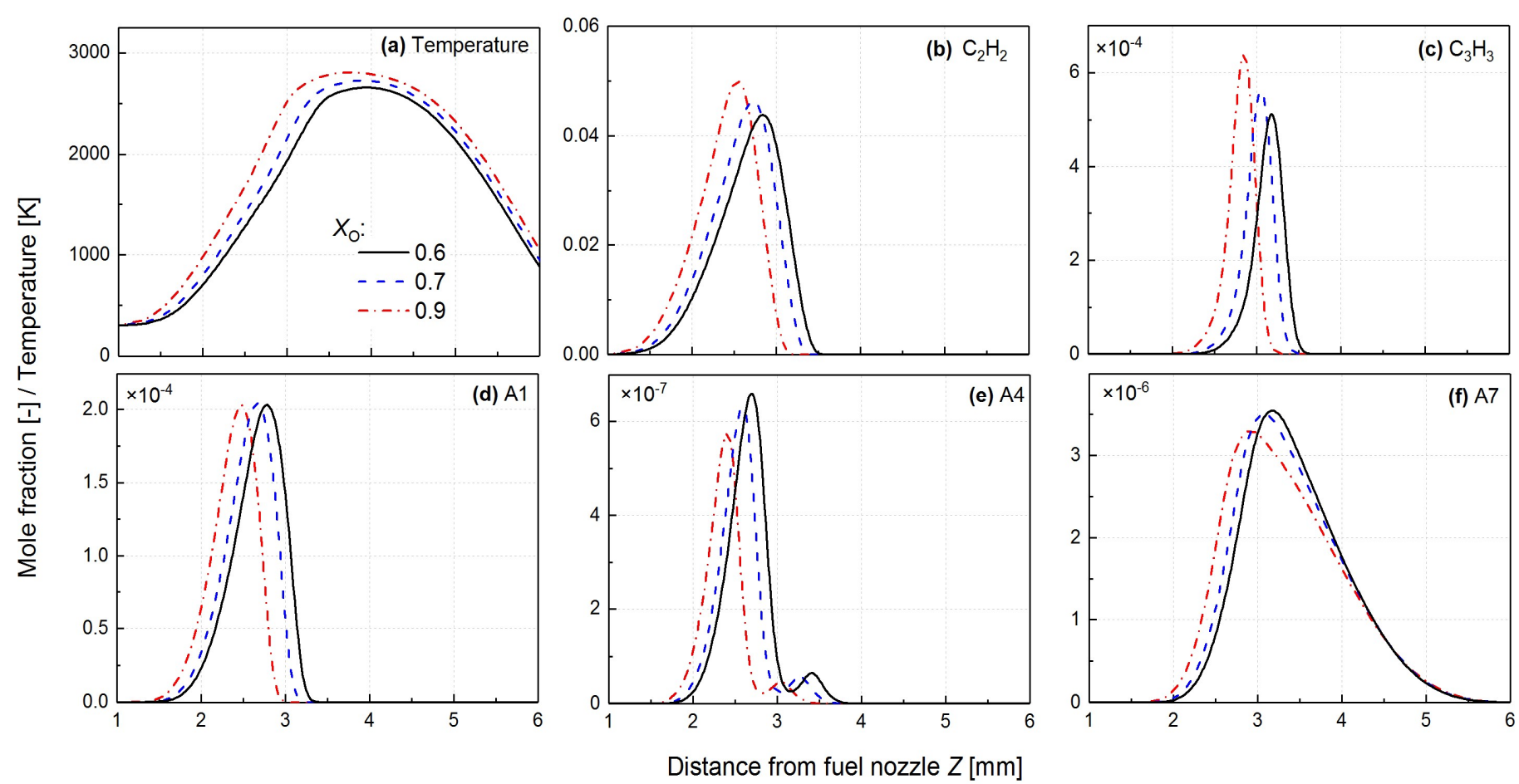

Fig. 9. Computed profiles of temperature, $\mathrm{C}_{2} \mathrm{H}_{2}, \mathrm{C}_{3} \mathrm{H}_{3}$ and aromatic species of $\mathrm{C}_{2} \mathrm{H}_{4}$ SFO flames with various $X_{\mathrm{O}}\left(X_{\mathrm{F}}=0.28\right.$; $X_{\mathrm{O}}=0.6,0.7$ and 0.9$)$.

These temperature and species profiles demonstrated monotonic variations with $X_{\mathrm{O}}$, such that further analysis is needed to explain the non-monotonic sooting behavior in the SFO flames, as shown in Fig. 10. Given that PAHs are molecular soot precursors, the reduction of PAH concentrations (although not shown, the concentration of A5 and A6 also decreased with $X_{\mathrm{O}}$ ) would naturally result in a decrease in soot inception rates as shown in Fig. 10a, where the total inception rates from the 36 dimerization reactions are shown. As $X_{\mathrm{O}}$ increases, the soot inception rates decrease, and the peak location shifts toward the fuel stream, consistent with the behavior of PAHs. Since the monotonic reduction in the soot inception rate with $X_{\mathrm{O}}$ does not explain the non-monotonic behavior of soot volume fraction, the effects of $X_{\mathrm{O}}$ on soot surface growth and oxidation are investigated. 

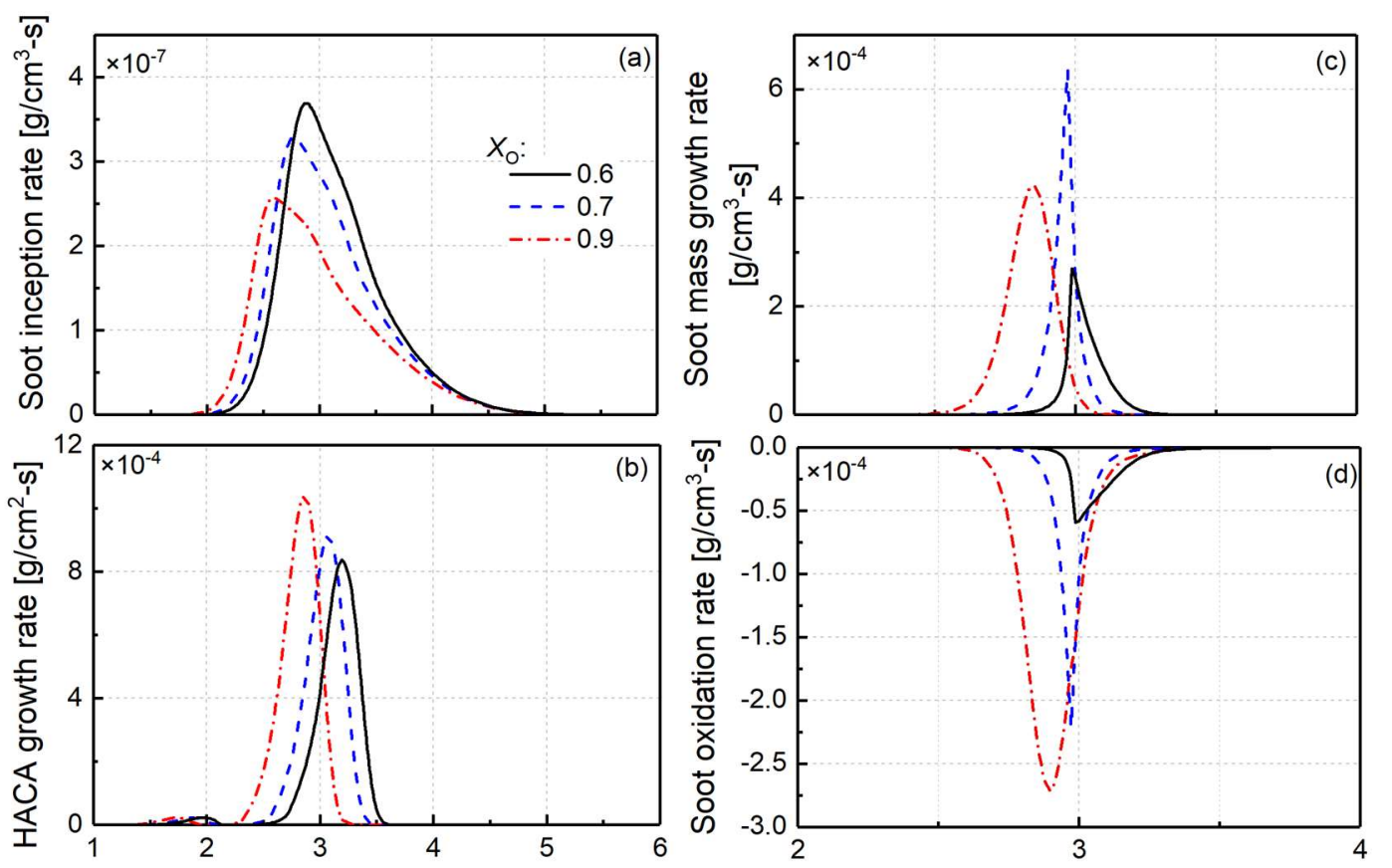

Distance from fuel nozzle $Z$ [mm]

Fig. 10. Computed (a) soot inception rates, (b) HACA growth rate $\left(\mathrm{g} / \mathrm{cm}^{2}-\mathrm{s}\right)$, (c) soot mass growth rate $\left(\mathrm{g} / \mathrm{cm}^{3}-\mathrm{s}\right)$ and (d) soot oxidation rate with $\mathrm{OH}$ radical for $\mathrm{C}_{2} \mathrm{H}_{4} \mathrm{SFO}$ flames with various $X_{\mathrm{O}}(0.6,0.7$ and 0.9$)$ for $X_{\mathrm{F}}=0.28$.

The HACA growth rate per unit surface area, $\omega_{\mathrm{s}}\left[\mathrm{g} / \mathrm{cm}^{2}\right.$-s] (Fig. 10b) shows a monotonic increase with $X_{\mathrm{O}}$, which is an opposite trend as compared with the soot inception rate. Noted that the spatial profiles of the HACA growth rate generally follow those of $\mathrm{C}_{2} \mathrm{H}_{2}$ mole fraction profiles shown in Fig. 9, with a slight shift toward the high-temperature region. This is expected because the surface-area normalized HACA growth rate is indeed a function of the $\mathrm{C}_{2} \mathrm{H}_{2}$ concentration and temperature, both of which tend to increase as less dilution is applied for high $X_{\mathrm{O}}$ cases.

It is important to note that the soot mass growth rates depend not only on $\omega_{\mathrm{s}}$ but also on available active surface sites for surface HACA reaction to occur. The soot mass growth rate, $\omega_{\mathrm{V}}\left[\mathrm{g} / \mathrm{cm}^{3}-\mathrm{s}\right]$ can be expressed as: $\omega_{\mathrm{V}} \propto_{\omega_{\mathrm{s}}} A_{\mathrm{s}}$, where $A_{\mathrm{S}}$ is the soot surface area density $\left[\mathrm{cm}^{2} / \mathrm{cm}^{3}\right]$. Although $\omega_{\mathrm{s}}$ increases with $X_{\mathrm{O}}$, the decrease in soot inception rates may suggest less surface area are available for efficient soot growth in the large $X_{\mathrm{O}}$ cases. As a result, the available surface area density $A_{\mathrm{S}}$ changes non-monotonically as $X_{\mathrm{O}}$ increases. Therefore, it can be concluded that changes in the soot inception rate and the HACA surface reaction rate $\left(\omega_{\mathrm{s}}\right)$ follow opposite trends as $X_{\mathrm{O}}$ increases, which could lead to the non-monotonic variation of $\omega_{\mathrm{V}}$ as confirmed in Fig. 10c. Specifically, as $X_{\mathrm{O}}$ increases from 0.6 to 0.7 , the number density of nascent soot particles reduces due to the decreased soot inception rate. However, the increase in the HACA surface 
growth rate overtakes and contributes to the increase in the soot surface area and thus soot mass growth. However, if $X_{\mathrm{O}}$ further increases to 0.9 , the decrease in soot particle numbers (and thus the available surface area $A_{\mathrm{s}}$ ) becomes the determining factor. As a consequence, the soot mass growth rate per unit volume exhibits a rise-then-fall variation with $X_{\mathrm{O}}$, which partly contributes to the observed non-monotonic variation of soot volume fractions with $X_{\mathrm{O}}$.

Also note that in the SFO flames, soot oxidation has a major role on the soot volume fraction. Figure 10d shows the soot oxidation rate $\left[\mathrm{g} / \mathrm{cm}^{3}-\mathrm{s}\right]$ by the attacks of $\mathrm{OH}$ radicals. The result shows that the maximum soot oxidation rate increases as $X_{\mathrm{O}}$ increases, which also contributes to the monotonic reduction of soot volume fraction. Note that soot oxidation with $\mathrm{O}_{2}$ also increases with increasing $X_{\mathrm{O}}$, however, the oxidation intensity is quite weak and thus not shown. The insignificance of oxidation by $\mathrm{O}_{2}$ can be partly due to the fact that there was almost no $\mathrm{O}_{2}$ present in the sooting region of $\mathrm{Z}=2.5-3.1 \mathrm{~mm}$ (see Fig. 6a and d) and therefore most of soot particles have been oxidized by $\mathrm{OH}$ radicals before reaching oxygen-rich condition. It is worthwhile to point out that previous over-ventilated coflow flame studies $[80,98]$ indicated that soot oxidation by $\mathrm{OH}$ had a major impact on the peak soot loading, while oxidation by $\mathrm{O}_{2}$ can be important in the post-flame oxidation region. It was also seen in certain SFO flames with a small amounts of oxygen added into the fuel stream [28] that the oxygen-driven oxidation and fragmentation can be active in the sooting region. These results on the importance of $\mathrm{O}_{2}$ are not inconsistent with the present work, considering abundant $\mathrm{O}_{2}$ exist in the post-flame zone of over-ventilated flame and fuel-side of SFO flame (due to fuel side oxygen addition) while nearly no $\mathrm{O}_{2}$ coexists with soot in the present $\mathrm{SFO}$ flame.

We conclude that the observed non-monotonic behavior in soot volume fraction with $X_{\mathrm{O}}$ is caused by the opposite trends of soot inception, soot surface growth, and soot oxidation. Specifically, the reduction in soot inception combined with increased soot oxidation with increased $X_{\mathrm{O}}$ lead to the decrease of soot volume fraction. However, the soot surface growth rate increases as $X_{\mathrm{O}}$ increases, which contribute to the increase in the soot concentration.

We next discuss the effects of $X_{\mathrm{O}}$ on soot formation in SF flames. As can be seen previously in Fig. 4, the peak soot volume fraction monotonically increases with $X_{\mathrm{O}}$. To further elucidate the different behavior of sooting tendency in SFO and SF flames, the profiles of temperature and important species are plotted in Fig. 11 for the SF flames. Similar to SFO 
flames, the result shows that as $X_{\mathrm{O}}$ increases, the maximum flame temperature (a) and the mole fractions of fuel pyrolysis products, $\mathrm{C}_{2} \mathrm{H}_{2}$ and $\mathrm{C}_{3} \mathrm{H}_{3}$ (b-c) increase. The major differences between the SF and SFO flames are that the concentrations of aromatic species, A1, A4 and A7 (e-f), increase with $X_{\mathrm{O}}$ in SF flames whereas they decrease in SFO flames (see Fig. 9).
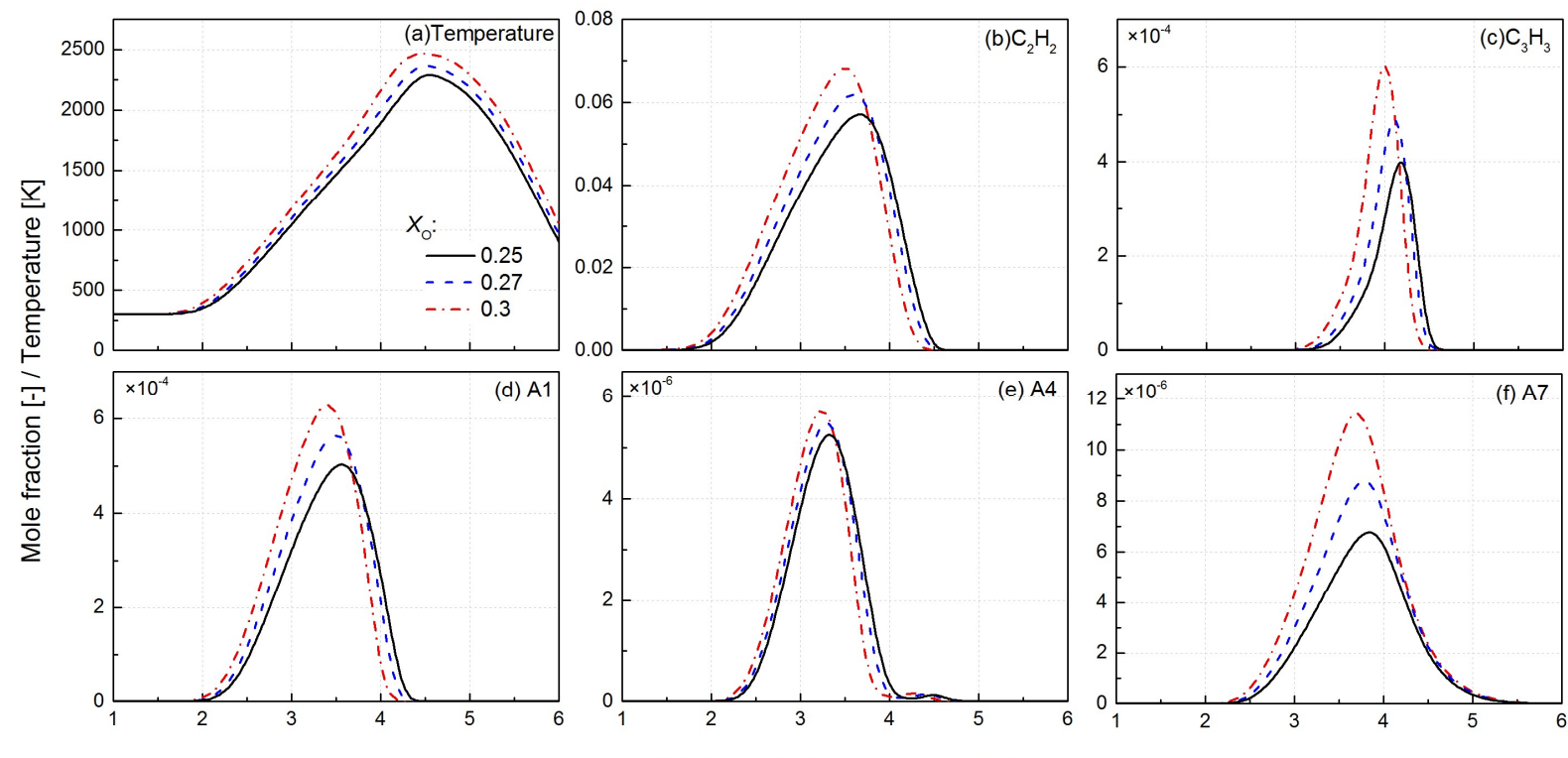

Distance from fuel nozzle $Z$ [mm]

Fig. 11. Computed flame temperature, $\mathrm{C}_{2} \mathrm{H}_{2}, \mathrm{C}_{3} \mathrm{H}_{3}$ and aromatic species of $\mathrm{C}_{2} \mathrm{H}_{4} \mathrm{SF}$ flames with various $X_{\mathrm{O}}\left(X_{\mathrm{F}}=1.0, X_{\mathrm{O}}=0.25\right.$, 0.27 and 0.3$)$.

The higher PAH concentrations with larger $X_{\mathrm{O}}$ for the SF flames result in an increase in the soot inception rates with $X_{\mathrm{O}}$, as shown in Fig. 12a. The HACA surface reaction rate (Fig. 12b) also increases monotonically with $X_{\mathrm{O}}$, which can be explained based on the increases in $\mathrm{C}_{2} \mathrm{H}_{2}$ concentration and flame temperature. Consequently, the combined higher soot inception and HACA reaction rates led to a monotonic increase in the soot mass growth rate $\left(\omega_{\mathrm{V}}\right)$ and thus the soot volume fraction in SF flames. Although the maximum soot oxidation intensity increases with $X_{\mathrm{O}}$ (Fig. 12c), the soot oxidation hardly occurs in the soot growth region of $Z=3.5-2.8 \mathrm{~mm}$, indicating the negligible effect of oxidation on the evolution of soot in this region. Since soot inception and HACA growth rates are both dependent on the flame temperature, the results also support previous observations that the sooting limit curve in the SF region follows isoflame temperature curve. 

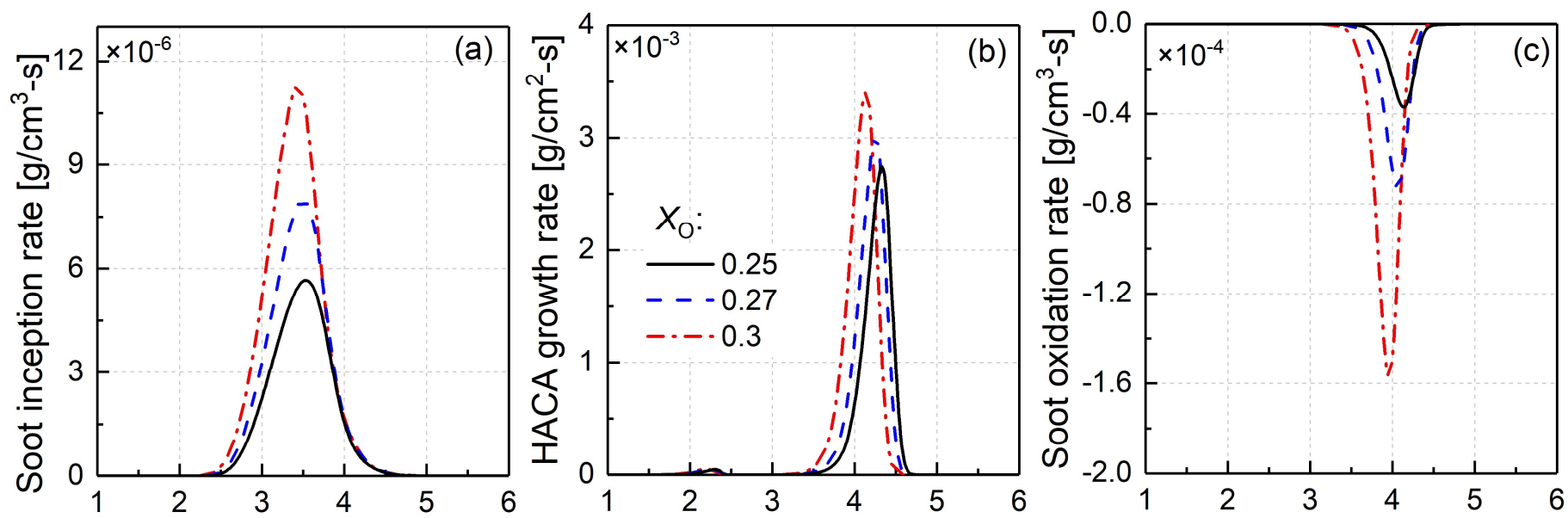

Distance from fuel nozzle $Z$ [mm]

Fig. 12. Computed (a) soot inception rate soot volume fraction, (b) HACA surface growth rate per unit surface area and (c) soot oxidation rate with $\mathrm{OH}$ radical of $\mathrm{C}_{2} \mathrm{H}_{4} \mathrm{SF}$ flames with various $X_{\mathrm{O}}\left(X_{\mathrm{F}}=1.0, X_{\mathrm{O}}=0.25,0.27\right.$ and 0.3$)$

\subsection{Further analysis on the PAH growth in SFO flames}

The aforementioned comparisons of soot evolution process indicate that the major difference in the SFO and SF flames is the soot inception process: the soot inception was suppressed with increasing $X_{\mathrm{O}}$ in SFO flames while enhanced in SF flames. For a deeper understanding on the non-monotonic variation of sooting tendency, the decrease of soot inception rate in the SFO flames need further explanation, which can be traced back to the reduction of larger aromatic species.

Since benzene formation is considered a critical step of the subsequent growth of larger aromatic species and thus the soot inception process, we have performed the rate of production (ROP) and sensitivity analysis for A1 species in SFO flame for $X_{\mathrm{O}}=0.7$. The ROP result in Fig. 13 indicates that A1 is primarily produced from reactions (R1): $2 \mathrm{C}_{3} \mathrm{H}_{3} \Leftrightarrow \mathrm{A} 1$ and (R2): A1- $+\mathrm{H}(+\mathrm{M}) \Leftrightarrow \mathrm{A} 1(+\mathrm{M})$. While the competing consumption of A1 is dominated by reaction (R3):A1- $+\mathrm{H}_{2}$ $\Leftrightarrow \mathrm{A} 1+\mathrm{H}$ and (R4): $\mathrm{C}_{4} \mathrm{H}_{5}-2\left(\mathrm{CH}_{3} \mathrm{C} \equiv \mathrm{CCH}_{2}\right)+\mathrm{C}_{2} \mathrm{H}_{2} \Leftrightarrow \mathrm{A} 1+\mathrm{H}$, both of which are reversible reactions and their reverse reactions are preferred in the present high flame temperature environment (the peak flame temperature exceeds $2700 \mathrm{~K}$ for $\left.X_{\mathrm{O}}=0.7\right)$. 


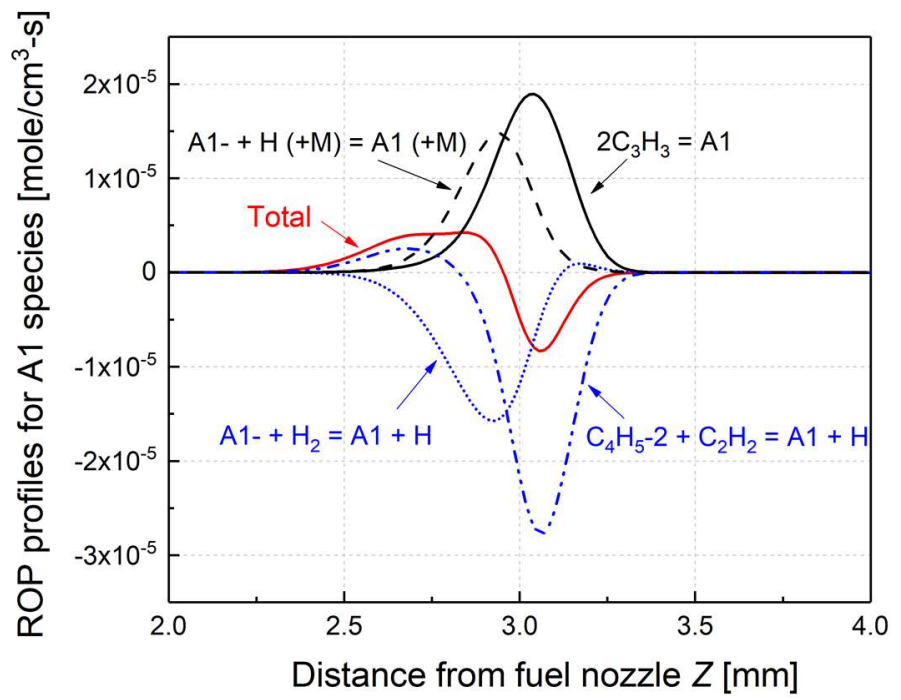

Fig. 13. Rate of production profiles for $\mathrm{A} 1$ species in $\mathrm{SFO}$ flame for $X_{\mathrm{F}}=0.28$ and $X_{\mathrm{O}}=0.7\left(\mathrm{C}_{4} \mathrm{H}_{5}-2\right.$ : $\left.\mathrm{CH}_{3} \mathrm{C} \equiv \mathrm{CCH}_{2}\right)$.

Although not shown, A1 productions from (R1) and (R2) increase monotonically with $X_{\mathrm{O}}$, which can be attributed to the increase of $\mathrm{C}_{3} \mathrm{H}_{3}$ concentration. Note that the radical A1- (phenyl) is primarily produced from the reaction (R5): $2 \mathrm{C}_{3} \mathrm{H}_{3} \Leftrightarrow \mathrm{A} 1-+\mathrm{H}$ which in turn partly converted into A1 through (R2). Meanwhile the A1 consumption through the reverse reactions of (R3) and (R4) are also enhanced with increasing $X_{\mathrm{O}}$, preventing the A1 formation. This can be partly due to the increased flame temperature with $X \mathrm{o}$ which favors the reverse reaction of (R3) and (R4). Furthermore, as shown in Fig. 14, the higher $\mathrm{H}$ radical concentration with larger $X_{\mathrm{O}}$ also promotes the A1 consumption through reactions (R3) and (R4). Consequently, these competing reactions restrict the increase of A1 production with $X_{\mathrm{O}}$.

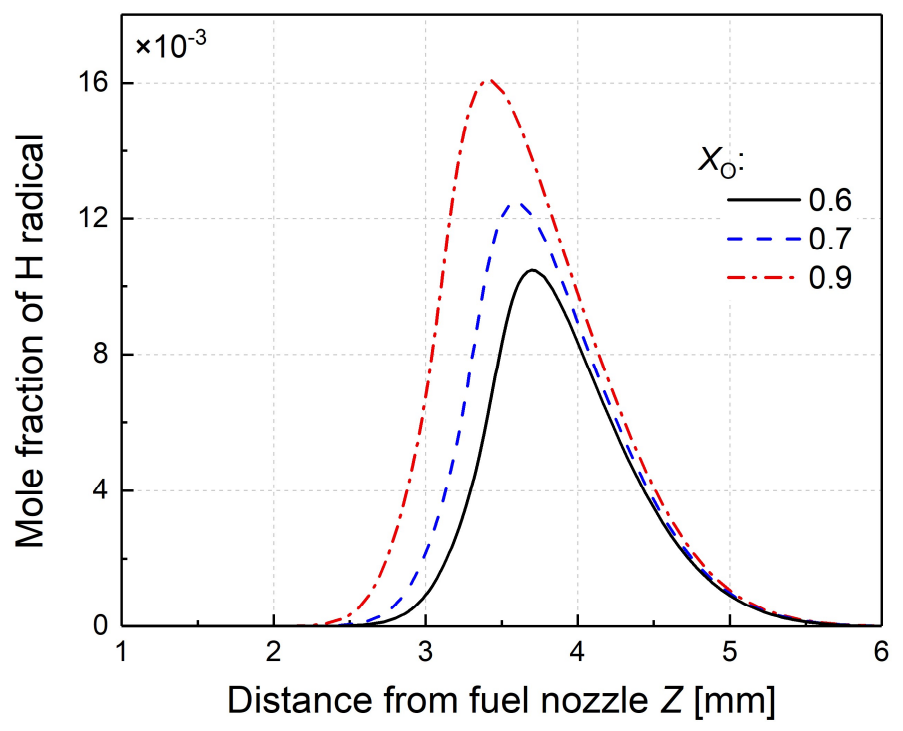

Fig. 14. The variation of $\mathrm{H}$ radical concentration in SFO flames with $X_{\mathrm{O}}=0.6,0.7$ and 0.9.

A sensitivity analysis on the $\mathrm{A} 1$ species for $X_{\mathrm{O}}=0.7$ has also been conducted. The location of $Z=2.68 \mathrm{~mm}$ where the 
A1 species profile peaks, was selected for the analysis. A positive (negative) coefficient indicates a promotion (inhibition) on A1 formation. As shown in Fig. 15, the reactions $2 \mathrm{C}_{3} \mathrm{H}_{3} \Leftrightarrow \mathrm{A} 1-+\mathrm{H}$ and $2 \mathrm{C}_{3} \mathrm{H}_{3} \Leftrightarrow$ A1 are two most influencing reactions on $\mathrm{A} 1$ formation, because of the dominant role of $\mathrm{C}_{3} \mathrm{H}_{3}$ in $\mathrm{A} 1$ formation, as discussed previously. While the reaction $\mathrm{C}_{2} \mathrm{H}_{3}(+\mathrm{M}) \Leftrightarrow \mathrm{C}_{2} \mathrm{H}_{2}+\mathrm{H}$ and $\mathrm{A} 1-(+\mathrm{M}) \Leftrightarrow \mathrm{c}-\mathrm{C}_{6} \mathrm{H}_{4}+\mathrm{H}(+\mathrm{M})$ mostly inhibit the A1 formation. This is because these two reactions produce abundant $\mathrm{H}$ radicals which tend to promote the A1 consumption reactions of (R3) and (R4). This result suggests the important inhibiting role of $\mathrm{H}$ radical on $\mathrm{A} 1$ formation. Therefore, it can be concluded that as $X_{\mathrm{O}}$ increases, the combined higher flame temperature and $\mathrm{H}$ radical concentration restrict the A1 formation in SFO flames.

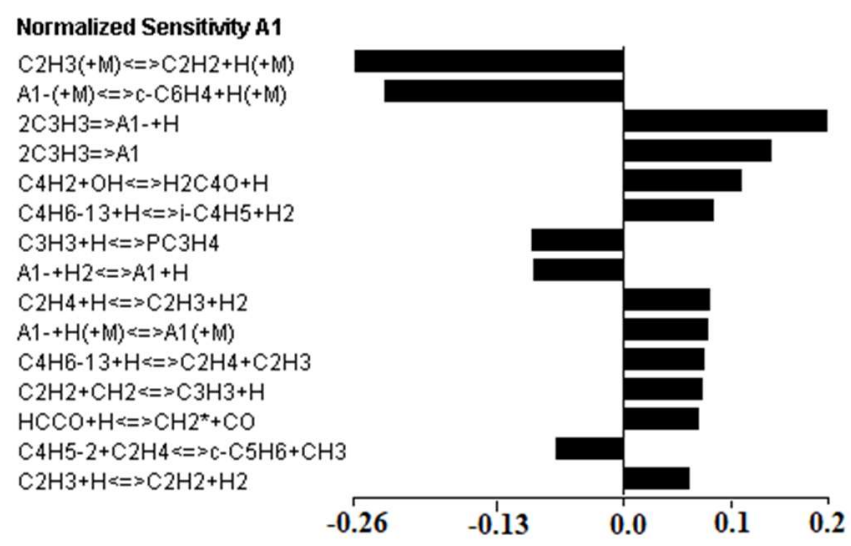

Fig. 15. Normalized sensitivity analysis of benzene species for case of $X_{\mathrm{O}}=0.7$. The sensitivity analysis results for case of $X_{\mathrm{O}}$ $=0.6$ and 0.9 are qualitatively similar to case of $X_{\mathrm{O}}=0.7$ and thus not presented.

Consequently, the A1 concentration remains almost unchanged as $X_{\mathrm{O}}$ increases. Note this result is different from the case of SF flames where the A1 concentration increases obviously with $X_{\mathrm{O}}$. Within the HACA PAH growth kinetics, the restriction of A1 formation could slow down the increase of larger aromatic species such as pyrene A4. However, this fact cannot fully explain the reduction of A4 concentration in SFO flames (Fig. 9e). For deeper insights, ROP analysis has been conducted for A4 species and the results (provided in the supplementary material) show that the total production rate of A4 species increases slightly with $X_{\mathrm{O}}$, which can be attributed to higher $\mathrm{C}_{2} \mathrm{H}_{2}$ concentration at larger case of $X_{\mathrm{O}}$. This result may seem confusing since a higher production rate tends to produce more A4 species. However, it is noted that besides the absolute production rate $\left(\mathrm{mole} / \mathrm{cm}^{3}-\mathrm{s}\right)$, the total produced A4 concentration also depends on 
the residence time available for $\mathrm{A} 4$ production. Indeed, as $X_{\mathrm{O}}$ increases the flame location shifts towards the fuel side, leading to increased flame temperature in the PAH growth region (Fig. 9). This in turn contributes to an increase in the axial velocity for SFO flames with higher $X_{\mathrm{O}}$. As a result, the residence time available for A4 production is decreased, which can be the reason for the reduced A4 concentration with increasing $X_{\mathrm{O}}$.

The reduction of larger PAHs (e.g., A7) with $X_{\mathrm{O}}$ can be attributed to both lower A4 concentration and reduced residence time for PAH growth reactions to occur. Consequently, opposed to the case of SF flames where larger PAHs and thus soot inception rate increases monotonically with $X_{\mathrm{O}}$, the soot inception rate in SFO flames even decreases with the increase in $X_{\mathrm{O}}$, which eventually contributes to its non-monotonic variation of soot mass growth rate and thus soot volume fraction.

\section{Concluding remarks}

In the present study, a combined experimental and numerical modelling study has been performed to investigate the effects of oxygen enrichment on the sooting characteristics of ethylene counterflow diffusion flames. Two types of flames having distinct sooting structures were investigated: soot formation-oxidation (SFO) and soot formation (SF) flames by varying the oxygen mole fraction. The major conclusions are as follows:

1. Both the computed and experimental results showed that for SFO flames, as $X_{\mathrm{O}}$ increases from 0.5 to 1.0 , the maximum soot volume fraction first increased, reaching a maximum near $X_{\mathrm{O}}=0.7$, and then decreased as $X_{\mathrm{O}}$ approached unity. In SF flames, the maximum soot volume fraction increased monotonically as $X_{\mathrm{O}}$ increased.

2. Detailed analysis of the soot modeling results revealed distinctive sooting structures between SFO and SF flames. In SFO flames, the OH-rich oxidizing zone sit across the stagnation plane such that the newly incepted soot particles on the fuel side of the flame were convected toward the oxidizing zone for intensive oxidation. In SF flames, the oxidizing zone is far away from the stagnation plane and on the oxidizer side. In this case, the nascent soot particles are convected through a non-oxidizing zone where continuous soot growth occurs without destructive oxidation. The differences in the evolution of soot in these two types of flames resulted in different soot volume fraction 
profiles: a nearly symmetric shape in SFO flame and highly skewed profile in SF flame.

3. In SFO flames, an increase in $X_{\mathrm{O}}$ resulted in a decrease in the soot inception rate and in the increase of soot oxidation, both of which contributed to the reduction of soot volume fractions. On the contrary, the surface-area-normalized HACA reaction rate increased with higher $X_{\mathrm{O}}$. These competing effects resulted in the observed non-monotonic behavior of the soot volume fraction with $X_{\mathrm{O}}$. They also explained the bending behavior in the sooting limit curve in the SFO regime. While in SF flames, an increase in $X_{\mathrm{O}}$ resulted in an increase in both the soot inception rate and the surface growth rate, leading to the monotonic increase in the soot volume fraction with increasing $X_{\mathrm{O}}$.

4. The decreased soot inception rate in SFO flames can be partly attributed to the inhibition of A1 formation with increasing $X_{\mathrm{O}}$. ROP results indicated that the high flame temperature environment of the present SFO flames favored the A1 consumption reactions of $\mathrm{C}_{4} \mathrm{H}_{5}-2+\mathrm{C}_{2} \mathrm{H}_{2} \Leftrightarrow \mathrm{A} 1+\mathrm{H}$ and $\mathrm{A} 1-+\mathrm{H}_{2} \Leftrightarrow \mathrm{A} 1+\mathrm{H}$ in which the reverse reactions became stronger with higher $X_{\mathrm{O}}$. Furthermore, the sensitivity analysis revealed the important role of $\mathrm{H}$ radical on inhibiting A1 formation.

\section{Acknowledgements}

This work is supported by the National Key R\&D Program of China (2017YFC0211201), Natural Science Foundation of China (51606136) and the 111 Project (B17034). SHC was supported by King Abdullah University of Science and Technology.

\section{References}

[1] I.M. Kennedy, The health effects of combustion-generated aerosols, Proc. Combust. Inst. 31 (2007) 2757-2770.

[2] S. Menon, J. Hansen, L. Nazarenko, Y. Luo, Climate effects of black carbon aerosols in China and India, Science 297 (2002) 2250-2253.

[3] T.C. Bond, S.J. Doherty, D.W. Fahey, P.M. Forster, T. Berntsen, B.J. DeAngelo, M.G. Flanner, S. Ghan, B. Kärcher, D. Koch, S. Kinne, Y. Kondo, P.K. Quinn, M.C. Sarofim, M.G. Schultz, M. Schulz, C. Venkataraman, H. Zhang, S. Zhang, N. Bellouin, S.K. Guttikunda, P.K. Hopke, M.Z. Jacobson, J.W. Kaiser, Z. Klimont, U. Lohmann, J.P. Schwarz, D. Shindell, T. Storelvmo, S.G. Warren, C.S. Zender, Bounding the role of black carbon in the climate system: A scientific assessment, J. Geophys. Res. - Atmos. 118 (2013) 5380-5552.

[4] M.Z. Jacobson, Strong radiative heating due to the mixing state of black carbon in atmospheric aerosols, Nature 409 (2001) 695 . 
[5] DieselNet. Emission Standards < https://www.dieselnet.com/standards/eu/hd.php $>$.

[6] A.E. Karataş, Ö.L. Gülder, Soot formation in high pressure laminar diffusion flames, Prog. Energ. Combust 38 (2012) 818-845.

[7] H. Wang, Formation of nascent soot and other condensed-phase materials in flames, Proc. Combust. Inst. 33 (2011) 41-67.

[8] H.A. Michelsen, Probing soot formation, chemical and physical evolution, and oxidation: A review of in situ diagnostic techniques and needs, Proc. Combust. Inst. 36 (2017) 717-735.

[9] C.S. McEnally, L.D. Pfefferle, B. Atakan, K. Kohse-Höinghaus, Studies of aromatic hydrocarbon formation mechanisms in flames: Progress towards closing the fuel gap, Prog. Energ. Combust 32 (2006) 247-294.

[10] B.R. Stanmore, J.F. Brilhac, P. Gilot, The oxidation of soot: a review of experiments, mechanisms and models, Carbon 39 (2001) 2247-2268.

[11] H. Richter, J.B. Howard, Formation of polycyclic aromatic hydrocarbons and their growth to soot-a review of chemical reaction pathways, Prog. Energ. Combust 26 (2000) 565-608.

[12] A. D'Anna, Combustion-formed nanoparticles, Proc. Combust. Inst. 32 (2009) 593-613.

[13] P. Singh, X. Hui, C.-J. Sung, Soot formation in non-premixed counterflow flames of butane and butanol isomers, Combust. Flame 164 (2016) 167-182.

[14] B.G. Sarnacki, H.K. Chelliah, Sooting limits of non-premixed counterflow ethylene/oxygen/inert flames using LII: Effects of flow strain rate and pressure (up to $30 \mathrm{~atm}$ ), Combust. Flame (2018).

[15] K. Gleason, F. Carbone, A. Gomez, Effect of temperature on soot inception in highly controlled counterflow ethylene diffusion flames, Combust. Flame 192 (2018) 283-294.

[16] F. Carbone, F. Cattaneo, A. Gomez, Structure of incipiently sooting partially premixed ethylene counterflow flames, Combust. Flame 162 (2015) 4138-4148.

[17] Q. Feng, A. Jalali, A.M. Fincham, Y.L. Wang, T.T. Tsotsis, F.N. Egolfopoulos, Soot formation in flames of model biodiesel fuels, Combust. Flame 159 (2012) 1876-1893.

[18] Y. Wang, S. Park, S.M. Sarathy, S.H. Chung, A comparative study on the sooting tendencies of various 1-alkene fuels in counterflow diffusion flames, Combust. Flame 192 (2018) 71-85.

[19] S. Park, Y. Wang, S.H. Chung, S.M. Sarathy, Compositional effects on PAH and soot formation in counterflow diffusion flames of gasoline surrogate fuels, Combust. Flame 178 (2017) 46-60.

[20] A. Violi, A. D’Anna, A. D’Alessio, A.F. Sarofim, Modeling aerosol formation in opposed-flow diffusion flames, Chemosphere 51 (2003) 1047-1054.

[21] S.A. Skeen, H.A. Michelsen, K.R. Wilson, D.M. Popolan, A. Violi, N. Hansen, Near-threshold photoionization mass spectra of combustion-generated high-molecular-weight soot precursors, J. Aerosol. Sci. 58 (2013) 86-102.

[22] U. Vandsburger, I. Kennedy, I. Glassman, Sooting Counterflow Diffusion Flames with Varying Oxygen Index, Combust. Sci. Technol. 39 (1984) 263-285.

[23] I. Glassman, Sooting laminar diffusion flames: Effect of dilution, additives, pressure, and microgravity, Symp. (Int.) Combust. 27 (1998) 1589-1596.

[24] A. Cuoci, A. Frassoldati, T. Faravelli, E. Ranzi, Formation of soot and nitrogen oxides in unsteady counterflow diffusion flames, Combust. Flame 156 (2009) 2010-2022.

[25] A. Cuoci, A. Frassoldati, T. Faravelli, E. Ranzi, Soot formation in unsteady counterflow diffusion flames, Proc. Combust. Inst. 32 (2009) 1335-1342.

[26] M. Sirignano, A. Collina, M. Commodo, P. Minutolo, A. D’Anna, Detection of aromatic hydrocarbons and incipient particles in an opposed-flow flame of ethylene by spectral and time-resolved laser induced emission spectroscopy, Combust. Flame 159 (2012) 1663-1669.

[27] A. D’Anna, M. Commodo, M. Sirignano, P. Minutolo, R. Pagliara, Particle formation in opposed-flow diffusion flames of ethylene: An experimental and numerical study, Proc. Combust. Inst. 32 (2009) 793-801.

[28] M. Sirignano, J. Kent, A. D’Anna, Further experimental and modelling evidences of soot fragmentation in flames, Proc. Combust. Inst. 35 (2015) 1779-1786.

[29] M. Sirignano, M. Conturso, A. D'Anna, Effect of furans on particle formation in diffusion flames: An experimental 
and modeling study, Proc. Combust. Inst. 35 (2015) 525-532.

[30] M. Salamanca, M. Sirignano, A. D'Anna, Particulate Formation in Premixed and Counter-flow Diffusion Ethylene/Ethanol Flames, Energ. Fuel 26 (2012) 6144-6152.

[31] M. Sirignano, M. Salamanca, A. D'Anna, The role of dimethyl ether as substituent to ethylene on particulate formation in premixed and counter-flow diffusion flames, Fuel 126 (2014) 256-262.

[32] P. Rodrigues, B. Franzelli, R. Vicquelin, O. Gicquel, N. Darabiha, Unsteady dynamics of PAH and soot particles in laminar counterflow diffusion flames, Proc. Combust. Inst. 36 (2017) 927-934.

[33] S.H. Chung, A. Violi, Insights on the nanoparticle formation process in counterflow diffusion flames, Carbon 45 (2007) 2400-2410.

[34] A.M. Vincitore, S.M. Senkan, Polycyclic Aromatic Hydrocarbon Formation in Opposed Flow Diffusion Flames of Ethane, Combust. Flame 114 (1998) 259-266.

[35] N. Olten, S. Senkan, Formation of polycyclic aromatic hydrocarbons in an atmospheric pressure ethylene diffusion flame, Combust. Flame 118 (1999) 500-507.

[36] N.A. Slavinskaya, U. Riedel, S.B. Dworkin, M.J. Thomson, Detailed numerical modeling of PAH formation and growth in non-premixed ethylene and ethane flames, Combust. Flame 159 (2012) 979-995.

[37] P.H. Joo, Y. Wang, A. Raj, S.H. Chung, Sooting limit in counterflow diffusion flames of ethylene/propane fuels and implication to threshold soot index, Proc. Combust. Inst. 34 (2013) 1803-1809.

[38] S.H. Chung, C.K. Law, Structure and extinction of convective diffusion flames with general Lewis numbers, Combust. Flame 52 (1983) 59-79.

[39] K.T. Kang, J.Y. Hwang, S.H. Chung, W. Lee, Soot zone structure and sooting limit in diffusion flames: Comparison of counterflow and co-flow flames, Combust. Flame 109 (1997) 266-281.

[40] J.Y. Hwang, S.H. Chung, Growth of soot particles in counterflow diffusion flames of ethylene, Combust. Flame 125 (2001) 752-762.

[41] J.Y. Hwang, W. Lee, H.G. Kang, S.H. Chung, Synergistic Effect of Ethylene-Propane Mixture on Soot Formation in Laminar Diffusion Flames, Combust. Flame 114 (1998) 370-380.

[42] D.X. Du, R. L. Axelbaum, C.K. Law, The influence of carbon dioxide and oxygen as additives on soot formation in diffusion flames, Proc. Combust. Inst. 23 (1991) 1501-1507.

[43] A. Beltrame, P. Porshnev, W. Merchan-Merchan, A. Saveliev, A. Fridman, L. Kennedy, O. Petrova, S. Zhdanok, F. Amouri, O. Charon, Soot and NO formation in methane-oxygen enriched diffusion flames, Combust. Flame 124 (2001) 295-310.

[44] C.P. Leusden, N. Peters, Experimental and numerical analysis of the influence of oxygen on soot formation in laminar counterflow flames of acetylene, Proc. Combust. Inst. 28 (2000) 2619-2625.

[45] Y. Wang, S.H. Chung, Effect of strain rate on sooting limits in counterflow diffusion flames of gaseous hydrocarbon fuels: Sooting temperature index and sooting sensitivity index, Combust. Flame 161 (2014) 1224-1234.

[46] S.A. Skeen, G. Yablonsky, R.L. Axelbaum, Characteristics of non-premixed oxygen-enhanced combustion: II. Flame structure effects on soot precursor kinetics resulting in soot-free flames, Combust. Flame 157 (2010) 1745-1752. [47] J. Du, R.L. Axelbaum, The effect of flame structure on soot-particle inception in diffusion flames, Combust. Flame 100 (1995) 367-375.

[48] F. Xia, G.S. Yablonsky, R.L. Axelbaum, Numerical study of flame structure and soot inception interpreted in carbon-to-oxygen atom ratio space, Proc. Combust. Inst. 34 (2013) 1085-1091.

[49] B.H. Chao, S. Liu, R.L. Axelbaum, On Soot Inception in Nonpremixed Flames and the Effects of Flame Structure, Combust. Sci. Technol. 138 (1998) 105-135.

[50] K.C. Kalvakala, V.R. Katta, S.K. Aggarwal, Effects of oxygen-enrichment and fuel unsaturation on soot and NOx emissions in ethylene, propane, and propene flames, Combust. Flame 187 (2018) 217-229.

[51] S.V. Naik, N.M. Laurendeau, J.A. Cooke, M.D. Smooke, A soot map for methane-oxygen counterflow diffusion flames, Combust. Sci. Technol 175 (2003) 1165-1177.

[52] K.C. Oh, H.D. Shin, The effect of oxygen and carbon dioxide concentration on soot formation in non-premixed flames, Fuel 85 (2006) 615-624. 
[53] Y. Jung, K.C. Oh, C. Bae, H.D. Shin, The effect of oxygen enrichment on incipient soot particles in inverse diffusion flames, Fuel 102 (2012) 199-207.

[54] K.-O. Lee, C. Megaridis, S. Zelepouga, A. V. Saveliev, L. Kennedy, O. Charon, F. Ammouri, Soot formation effects of oxygen concentration in the oxidizer stream of laminar coannular nonpremixed methane/air flames, Combust. Flame 121 (2000) 323-333.

[55] Glassman, P. Yaccarino, The Effect of Oxygen Concentration on Sooting Diffusion Flames, Combust. Sci. Technol. 24 (1980) 107-114.

[56] R. Henríquez, R. Demarco, J.L. Consalvi, F. Liu, A. Fuentes, The Oxygen Index on Soot Production in Propane Diffusion Flames, Combust. Sci. Technol. 186 (2014) 504-517.

[57] Q. Wang, G. Legros, J. Bonnety, C. Morin, A. Matynia, J.-L. Consalvi, F. Liu, Experimental assessment of the sudden-reversal of the oxygen dilution effect on soot production in coflow ethylene flames, Combust. Flame 183 (2017) 242-252.

[58] V. Chernov, Q. Zhang, M.J. Thomson, S.B. Dworkin, Numerical investigation of soot formation mechanisms in partially-premixed ethylene-air co-flow flames, Combust. Flame 159 (2012) 2789-2798.

[59] H.P. Mungekar, A. Atreya, Effect of partial premixing on the sooting structure of methane flames, Combust. Flame 144 (2006) 336-348.

[60] A. Beltrame, P. Porshnev, W. Merchan-Merchan, A. Saveliev, A. Fridman, L.A. Kennedy, O. Petrova, S. Zhdanok, F. Amouri, O. Charon, Soot and NO formation in methane-oxygen enriched diffusion flames, Combust. Flame 124 (2001) 295-310.

[61] Y. Wang, S.H. Chung, Strain rate effect on sooting characteristics in laminar counterflow diffusion flames, Combust. Flame 165 (2016) 433-444.

[62] Y. Wang, A. Raj, S.H. Chung, Soot modeling of counterflow diffusion flames of ethylene-based binary mixture fuels, Combust. Flame 162 (2015) 586-596.

[63] D. Diso, M.R. Perrone, M.L. Protopapa, Beam width measurements of asymmetric multi-mode laser beams, Opt Laser Technol 31 (1999) 411-418.

[64] M.P.B. Musculus, L.M. Pickett, Diagnostic considerations for optical laser-extinction measurements of soot in highpressure transient combustion environments, Combust. Flame 141 (2005) 371-391.

[65] R.J. Santoro, H.G. Semerjian, R.A. Dobbins, Soot particle measurements in diffusion flames, Combust. Flame 51 (1983) 203-218.

[66] C.J. Dasch, One-dimensional tomography: a comparison of Abel, onion-peeling, and filtered backprojection methods, Appl Opt 31 (1992) 1146-1152.

[67] J. Zerbs, K.P. Geigle, O. Lammel, J. Hader, R. Stirn, R. Hadef, W. Meier, The influence of wavelength in extinction measurements and beam steering in laser-induced incandescence measurements in sooting flames, Appl. Phys. B. 96 (2009) 683-694.

[68] J. Simonsson, N.-E. Olofsson, S. Török, P.-E. Bengtsson, H. Bladh, Wavelength dependence of extinction in sooting flat premixed flames in the visible and near-infrared regimes, Appl. Phys. B. 119 (2015) 657-667.

[69] F. Migliorini, K.A. Thomson, G.J. Smallwood, Investigation of optical properties of aging soot, Appl. Phys. B. 104 (2011) 273-283.

[70] S. Bejaoui, X. Mercier, P. Desgroux, E. Therssen, Laser induced fluorescence spectroscopy of aromatic species produced in atmospheric sooting flames using UV and visible excitation wavelengths, Combust. Flame 161 (2014) 2479-2491.

[71] M. Leschowski, K.A. Thomson, D.R. Snelling, C. Schulz, G.J. Smallwood, Combination of LII and extinction measurements for determination of soot volume fraction and estimation of soot maturity in non-premixed laminar flames, Appl. Phys. B. 119 (2015) 685-696.

[72] Y. Wang, A. Raj, S.H. Chung, A PAH growth mechanism and synergistic effect on PAH formation in counterflow diffusion flames, Combust. Flame 160 (2013) 1667-1676.

[73] H. Wang, X. You, A. Joshi, S. Davis, A. Laskin, F.N. Egolfopoulos, C.K. Law, USC Mech Version II, http://ignis.usc.edu/USC_Mech_II.htm (2007). 
[74] A. Raj, M. Sander, V. Janardhanan, M. Kraft, A study on the coagulation of polycyclic aromatic hydrocarbon clusters to determine their collision efficiency, Combust. Flame 157 (2010) 523-534.

[75] M. Frenklach, H. Wang, Detailed modeling of soot particle nucleation and growth, Symp. (Int.) Combust. 23 (1991) 1559-1566.

[76] J. Appel, H. Bockhorn, M. Frenklach, Kinetic modeling of soot formation with detailed chemistry and physics: Laminar premixed flames of C-2 hydrocarbons, Combust. Flame 121 (2000) 122-136.

[77] S.J. Harris, I.M. Kennedy, The Coagulation of Soot Particles with van der Waals Forces, Combust. Sci. Technol. 59 (1988) 443-454.

[78] J. Appel, H. Bockhorn, M. Frenklach, Kinetic modeling of soot formation with detailed chemistry and physics: laminar premixed flames of C 2 hydrocarbons, Combust. Flame 121 (2000) 122-136.

[79] M.S. Celnik, M. Sander, A. Raj, R.H. West, M. Kraft, Modelling soot formation in a premixed flame using an aromatic-site soot model and an improved oxidation rate, Proc. Combust. Inst. 32 (2009) 639-646.

[80] A. Khosousi, S.B. Dworkin, Detailed modelling of soot oxidation by $\mathrm{O}_{2}$ and $\mathrm{OH}$ in laminar diffusion flames, Proc. Combust. Inst. 35 (2015) 1903-1910.

[81] H. Guo, P.M. Anderson, P.B. Sunderland, Optimized rate expressions for soot oxidation by $\mathrm{OH}$ and $\mathrm{O}_{2}$, Fuel 172 (2016) 248-252.

[82] A. Raj, S.Y. Yang, D. Cha, R. Tayouo, S.H. Chung, Structural effects on the oxidation of soot particles by $\mathrm{O}_{2}$ : Experimental and theoretical study, Combust. Flame 160 (2013) 1812-1826.

[83] I.C. Jaramillo, C.K. Gaddam, R.L. Vander Wal, C.-H. Huang, J.D. Levinthal, J.S. Lighty, Soot oxidation kinetics under pressurized conditions, Combust. Flame 161 (2014) 2951-2965.

[84] S.B. Dworkin, Q. Zhang, M.J. Thomson, N.A. Slavinskaya, U. Riedel, Application of an enhanced PAH growth model to soot formation in a laminar coflow ethylene/air diffusion flame, Combust. Flame 158 (2011) 1682-1695.

[85] A. Veshkini, N.A. Eaves, S.B. Dworkin, M.J. Thomson, Application of PAH-condensation reversibility in modeling soot growth in laminar premixed and nonpremixed flames, Combust. Flame 167 (2016) 335-352.

[86] M. Sirignano, J. Kent, A. D’Anna, Modeling Formation and Oxidation of Soot in Nonpremixed Flames, Energ. Fuel 27 (2013) 2303-2315.

[87] M. Frenklach, Method of moments with interpolative closure, Chem. Eng. Sci. 57 (2002) 2229-2239.

[88] Y. Wang, S.H. Chung, Formation of Soot in Counterflow Diffusion Flames with Carbon Dioxide Dilution, Combust. Sci. Technol. 188 (2016) 805-817.

[89] M.Y. Choi, G.W. Mulholland, A. Hamins, T. Kashiwagi, Comparisons of the Soot Volume Fraction Using Gravimetric and Light Extinction Techniques, Combust. Flame 102 (1995) 161-169.

[90] H. Bladh, N.E. Olofsson, T. Mouton, J. Simonsson, X. Mercier, A. Faccinetto, P.E. Bengtsson, P. Desgroux, Probing the smallest soot particles in low-sooting premixed flames using laser-induced incandescence, Proc. Combust. Inst. 35 (2015) 1843-1850.

[91] A. Gomez, D.E. Rosner, Thermophoretic Effects on Particles in Counterflow Laminar Diffusion Flames, Combust. Sci. Technol 89 (1993) 335-362.

[92] R.S. Barlow, A.N. Karpetis, J.H. Frank, J.Y. Chen, Scalar profiles and NO formation in laminar opposed-flow partially premixed methane/air flames, Combust. Flame 127 (2001) 2102-2118.

[93] ANSYS Chemkin 17.0 (15151), Reaction Design: San Diego, 2015.

[94] J.-L. Consalvi, F. Liu, J. Contreras, M. Kashif, G. Legros, S. Shuai, J. Wang, Numerical study of soot formation in laminar coflow diffusion flames of methane doped with primary reference fuels, Combust. Flame 162 (2015) 1153-1163. [95] A. Khosousi, F. Liu, S.B. Dworkin, N.A. Eaves, M.J. Thomson, X. He, Y. Dai, Y. Gao, F. Liu, S. Shuai, J. Wang, Experimental and numerical study of soot formation in laminar coflow diffusion flames of gasoline/ethanol blends, Combust. Flame 162 (2015) 3925-3933.

[96] C.P. Leusden, N. Peters, Experimental and numerical analysis of the influence of oxygen on soot formation in laminar counterflow flames of acetylene, Proc. Combust. Inst. 28 (2000) 2619-2625.

[97] M.R. Kholghy, Y. Afarin, A.D. Sediako, J. Barba, M. Lapuerta, C. Chu, J. Weingarten, B. Borshanpour, V. Chernov, M.J. Thomson, Comparison of multiple diagnostic techniques to study soot formation and morphology in a diffusion 
flame, Combust. Flame 176 (2017) 567-583.

[98] A. Jerez, J.-L. Consalvi, A. Fuentes, F. Liu, R. Demarco, Soot production modeling in a laminar coflow ethylene diffusion flame at different Oxygen Indices using a PAH-based sectional model, Fuel 231 (2018) 404-416. 